\title{
Proteomic interrogation of the pathogen-host interface in cholera
}

Abdelrahim Zoued ${ }^{1,2,3}$, Hailong Zhang ${ }^{1,2,3}$, Ting Zhang $^{1,2}$, Rachel T. Giorgio ${ }^{2}$, Carole J. Kuehl $^{1,2,3}$, Bolutife Fakoya ${ }^{1,2}$, Brandon Sit $^{1,2}$, Matthew K. Waldor ${ }^{1,2,3 *}$

${ }^{1}$ Division of Infectious Diseases, Brigham and Women's Hospital, Boston, Massachusetts, USA

${ }^{2}$ Department of Microbiology, Harvard Medical School, Boston, Massachusetts, USA

${ }^{3}$ Howard Hughes Medical Institute, Boston, Massachusetts, USA

* Correspondence: mwaldor@ research.bwh.harvard.edu 


\section{Summary}

2 The microbial cell surface is a critical site of microbe-host interactions that often control

3 infection outcomes. Here, using the infant rabbit model of cholera, which provides an abundant

4 source of in vivo Vibrio cholerae cells and diarrheal fluid, we investigated the proteomic

5 composition of this interface. Bulk diarrheal fluid proteomes revealed that cholera toxin accounts

6 for the vast majority of the host proteins present during infection. We developed a surface

7 biotinylation protocol to purify and quantify both bacterial and host proteins present on the

8 surface of diarrheal fluid-derived V. cholerae. We found that SP-D, a toxin-dependent host

9 protein that directly binds the $V$. cholerae surface, is a novel intestinal defense factor. Other $V$.

10 cholerae-bound host proteins also bound distinct taxa of the murine intestinal microbiota.

11 Proteomic investigation of the microbial surface-host interface should be a valuable tool for

12 probing microbe-host interactions and their influence on homeostasis and infection.

\section{Keywords}

15 Cell-surface proteomics, host-pathogen interactions, cholera, Vibrio cholerae, microbiota 


\section{Introduction}

The principal interaction site between microbes and their hosts is found at the microbial cell surface. Microbial surface proteins, such as pili, adhesins, and receptors often mediate direct

27 interactions with host cells as well as the host milieu, facilitating microbial growth (1-3).

28 Conversely, host-derived proteins such as antimicrobial peptides, antibodies, and complement

29 bind to the bacterial surface and often restrict microbe growth (1). To date, comprehensive

30 characterization of the bacterial cell surface proteome or the host proteins that bind the pathogen

31 during infection has been challenging, due in part to the technical constraint of obtaining

32 sufficient quantities of in vivo pathogen cells for analysis. However, recent advances in tandem

33 mass tag (TMT) mass spectrometry (TMT-MS), and the availability of cell-impermeable protein

34 labeling reagents (4-9), suggest that the development of new approaches to monitor the

35 proteome of the microbial surface in vivo, including at the pathogen-host interface during

36 infection, should be feasible.

37 The rod-shaped, Gram-negative bacterium Vibrio cholerae causes the severe and

38 potentially lethal diarrheal disease cholera, which remains a significant threat to global public

39 health. Cholera has afflicted humans for centuries, remains endemic in over 50 countries (10)

40 and has caused major recent outbreaks, e.g. in Haiti and Yemen $(11,12)$. Cholera is caused by

41 consumption of food or water containing $V$. cholerae. The hallmark symptom of cholera is large

42 quantities (up to 20L/day in severe cases) of watery diarrhea, which can contain up to $10^{9} \mathrm{cfu} / \mathrm{ml}$

43 of $V$. cholerae (13). The production of choleric diarrhea is thought to promote the pathogen's

44 dissemination in the environment and subsequent transmission to naïve hosts.

45 Studies in human volunteers have established that choleric diarrhea is caused by the

46 activity of cholera toxin (CT), an $\mathrm{AB}_{5}$-type toxin that is secreted by $V$. cholerae in the small 
47 intestine (10,14-16). The enzymatic A subunit of CT catalyzes the ADP-ribosylation and

48 constitutive activation of $\mathrm{G}_{\mathrm{s}}$ alpha subunits within small intestinal epithelial cells, increasing the

49 activity of adenylate cyclase and leading to elevated intracellular cAMP concentrations, which in

50 turn stimulate active efflux of sodium $\left(\mathrm{Na}^{+}\right)$, chloride $\left(\mathrm{Cl}^{-}\right)$, potassium $\left(\mathrm{K}^{+}\right)$, bicarbonate $\left(\mathrm{HCO}_{3}{ }^{-}\right)$,

51 and water out of the cells $(10,17)$. Orogastric inoculation of purified CT is sufficient to trigger

52 cholera-like diarrhea in humans (18). Human studies have also revealed the importance of the

53 toxin co-regulated pilus (TCP), a V. cholerae cell surface appendage whose expression in vivo is

54 activated by the same virulence regulatory network as CT, and is essential for colonization of the

55 small intestine (19). Additional surface-associated factors, e.g. heme transport proteins and outer

56 membrane proteins (OMPs) also facilitate $V$. cholerae survival and growth in the small intestine

$57(20-22)$.

58 Cholera is restricted to humans, but several animal models have been developed to study

$59 V$. cholerae intestinal colonization and diarrheal disease (23). Much has been learned regarding

$60 V$. cholerae in vivo biology and pathogenicity from suckling ( 3-day-old) rabbits, where

61 orogastric inoculation with $V$. cholerae leads to robust intestinal colonization and a disease that

62 closely mimics severe human cholera (24). As in humans (19), $V$. cholerae intestinal

63 colonization is TCP-dependent in this model. Moreover, infant rabbits develop large volumes of

64 CT-dependent watery diarrheal fluid, and CT is also sufficient to induce diarrhea in these

65 animals (24). In infant rabbits, diarrheal fluid accumulates to high levels in the cecum

66 (approximately $0.5-1 \mathrm{~mL} / \mathrm{animal})$ prior to excretion. The fluid contains a high density $\left(10^{9}-10^{10}\right.$

$67 \mathrm{cfu}$ ) of $V$. cholerae, and thus provides a relatively pure source of in vivo organisms that has been

68 leveraged for various high-throughput investigations, including RNA-seq analyses of the 
69 pathogen's in vivo transcriptome (25) and Tn-Seq analyses of its genetic requirements for in vivo 70 growth (26-29).

71 Limited analyses of the $V$. cholerae proteome in vivo $(30,31)$ have been reported.

72 Previous efforts using activity-based protein profiling (ABBP) defined the active serine

73 hydrolases in diarrheal fluid of infant rabbits (32). This study suggested that secreted $V$. cholerae

74 proteases, including IvaP, decreased the activity of host proteases in diarrheal fluid $(32,33)$. This

75 work also suggested that the amount of intelectin, a host intestinal lectin bound to V. cholerae in

76 vivo was reduced by secreted $V$. cholerae proteases. This observation raised the intriguing

77 possibility that the pathogen is bound and/or targeted by a previously undefined set of host

78 proteins as it transits through the gastrointestinal tract. However, studies to define the diarrheal

79 fluid proteome and the role of $V$. cholerae factors in triggering the release of host proteins have

80 not been reported.

81 Here, we used the infant rabbit model of cholera and TMT-MS to define the bulk

82 proteome of choleric diarrhea. Additional TMT-MS analyses of surface labelled diarrheal fluid-

83 derived V. cholerae cells (in an approach termed Surface Protein LAbelingS Host/Microbe,

84 SPLASH/M) enabled identification of both pathogen and host proteins present at this interface.

85 Unexpectedly, we discovered that CT accounts for nearly the complete set of >1000 proteins

86 identified in diarrheal fluid. We found that one of the most abundant CT-dependent proteins,

87 surfactant protein D (SP-D), directly binds $V$. cholerae and functions as a region-specific

88 intestinal defense factor. SPLASH/M identified the suite of in vivo $V$. cholerae cell surface

89 proteins and also revealed a number of host-derived bacterial-binding proteins (HBBP), that

90 were not previously known to interact with bacteria. In addition to SP-D and Intelectin, these

91 HBBPs include Lactoperoxidase, Annexin A1 and Zinc-Alpha-Glycoprotein. Notably, we found 
92 that these proteins could not only associate with $V$. cholerae, but with the surfaces of a subsets of

93 murine gut symbiotic bacteria, suggesting that HBBPs may facilitate intestinal bacterial

94 homeostasis. The SPLASH/M approach provides a new lens to reveal the pathogen-host

95 interface and should be applicable to define the microbe-host proteomic interface in a wide

96 variety of settings.

97

\section{$98 \quad$ Results}

\section{Cholera toxin drives the host proteomic response to Vibrio cholerae}

100 To investigate how CT impacts the host proteomic response to $V$. cholerae, we used the 101 infant rabbit model of cholera. The chemistry of the diarrheal fluid that accumulates in the cecum

102 in this model resembles that of choleric fluid (24), but its proteomic composition has been less

103 characterized. In particular, while CT is known to induce secretion of $\mathrm{Cl}^{-}$and water into the

104 intestinal lumen, the pathogen factors that lead to the accumulation of proteins in choleric fluid

105 are unknown. Infant rabbits were oro-gastrically inoculated with wild-type (WT) V. cholerae (an

106 isolate from the Haiti 2010 outbreak (34)), a derivative of the WT strain containing a deletion of

$107 \operatorname{ctxAB}$ (V. cholerae $\Delta c t x)$, or purified CT $(50 \mu \mathrm{g})$, to assess the contribution of CT in stimulating

108 the proteomic response to $V$. cholerae intestinal colonization (Fig. 1A). Mock infected rabbits

109 that were inoculated with buffer only served as a negative control in these experiments.

110 Consistent with previous reports $(35,36)$, the burden of WT and V. cholerae $\Delta$ ctx in the diarrheal

111 fluid were similar, but there was much greater abundance of diarrheal fluid in the animals that

112 were inoculated with WT versus $\Delta c t x V$. cholerae (Fig. S1B). There was at least as much cecal

113 fluid recovered from animals inoculated with $\mathrm{CT}$ alone as animals inoculated with WT $V$.

114 cholerae, supporting the idea that $\mathrm{CT}$ is the major determinant of fluid accumulation in this 
model. There was a small amount of diarrheal fluid obtained from mock infected animals that

116 was sufficient for proteomic analysis.

118 analyze the protein composition of the diarrheal fluid isolated from the four groups of rabbits.

119 The 5968 peptides identified in this analysis were mapped to the rabbit proteome (37) and

120 corresponded to 1014 different proteins including 664 identified with more than 1 peptide (Fig.

121 1B, Table S1). Most of the proteins were predicted to be extracellular (Fig. S1C), consistent with

122 the idea that $V$. cholerae intestinal colonization does not disrupt the integrity of the intestinal

123 epithelial barrier $(10,15)$ and lead to the release of cytoplasmic proteins into the intestinal lumen.

124 Unexpectedly, both unsupervised hierarchical clustering and principal component analysis

125 revealed that the protein composition of fluid from animals infected with $V$. cholerae $\Delta c t x$ was

126 very similar to that in control animals, suggesting that in the absence of CT, V. cholerae

127 intestinal colonization does little to alter the secretion/release of host proteins into the intestinal

128 lumen (Fig. 1B-C). These analyses also revealed that the protein composition of fluid from

129 animals infected with WT $V$. cholerae or treated with CT alone were very similar (Fig. 1B-C-D).

130 Relative fold changes in individual protein abundance in samples from animals given CT only or

131 infected with WT $V$. cholerae were strongly correlated $(\mathrm{r}=0.93)$, further underscoring the

132 similarity of the proteomic signatures of these fluids (Fig. 1D, S1D). Together, these

133 observations strongly suggest that the activity of CT, in addition to triggering the secretory

134 response of ion and water flow into the intestinal lumen, also drives the secretion/release of

135 hundreds of proteins that are found in the cholera-like diarrheal fluid of infant rabbits.

136 Pathway enrichment analysis revealed several pathways specifically associated with WT $V$.

137 cholerae infection and CT treatment (Fig 1E, Table S2). These included several GO Biological 
138 Process terms linked to immune responses, including "immunoglobulin production" and

139 "defense response to bacterium", suggesting that CT plays a role in modulation of the immune

140 response to $V$. cholerae. WT $V$. cholerae infection and CT treatment also led to similar

141 reductions in relative abundances of proteins classified as regulators of proteolysis, raising the

142 possibility that CT modifies host protease activity.

SP-D directly binds $V$. cholerae and is an intestinal mucosal defense factor

One of the most abundant proteins in diarrheal fluid samples from animals infected with WT

$146 V$. cholerae or given CT was surfactant protein D (SP-D). SP-D is a C-type lectin that mediates

147 pulmonary innate immune defense and has been recently reported to function in intestinal

148 homeostasis by impacting the composition of the gut microbiota (38-41). The proteomic data

149 suggested that SP-D was $\sim 60$-fold enriched in the CT-only and WT $V$. cholerae infections

150 compared to the mock infected controls (Fig. 1D, red dot). Western blotting of filtered diarrheal

151 fluid from uninfected and WT-infected rabbits with a polyclonal anti-SP-D antibody confirmed

152 that rabbit SP-D was highly enriched in diarrheal fluid from infected rabbits (Fig. 2A)

153 We wondered whether this CT-induced lectin binds to V. cholerae during infection. To test

154 this possibility, V. cholerae cells were isolated from the diarrheal fluid of infected infant rabbits,

155 filtered, washed, lysed, and immunoblotted for SP-D. We readily detected SP-D in the $V$.

156 cholerae collected from the diarrheal fluid, suggesting that SP-D associates with $V$. cholerae

157 cells in vivo (Fig. 2B). Immunofluorescence microscopy was used to further investigate the

158 association of SP-D and $V$. cholerae in situ during infection. In these experiments, infant rabbits

159 were inoculated with a fluorescently-tagged wild-type $V$. cholerae strain (V. cholerae GFP) and

160 sections from the small intestines of infected animals were stained with an antibody to SP-D 
161 (Fig. 2C, S2A). Both V. cholerae and SP-D co-localized to the region immediately above the

162 epithelium (Fig. 2C), whereas staining with the secondary antibody used to detect the antibody to

163 SP-D did not bind to rabbit tissue on its own (Fig. S2A). At higher magnification (Fig. 2C, see

164 zoom), SP-D and V. cholerae GFP localize within the same matrix. A similar staining pattern

165 was reported for WGA-positive mucin aggregates in $V$. cholerae-infected rabbits (24),

166 suggesting that SP-D might co-localize with mucin and V. cholerae during infection.

167 SP-D harbors a C-terminal carbohydrate recognition domain that mediates its interactions

168 with microorganisms $(38,42,43)$. We adapted a previously described bacterial whole-cell 'pull-

169 down'-like assay (32), using purified SP-D protein, to test whether this protein could directly

170 bind $V$. cholerae. In these experiments, $V$. cholerae cells grown in vitro were incubated with

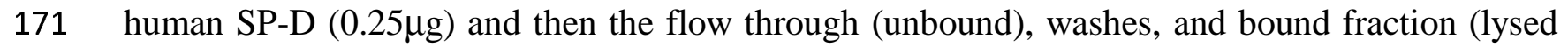

172 cells) were analyzed for the presence of SP-D using immunoblots. A band corresponding to SP-

$173 \mathrm{D}$, as detected in the positive control (SP-D lane), was observed in the flow through and bound

174 fractions, whereas almost no SP-D was detected in the two wash fractions. These observations

175 demonstrate that SP-D can directly interact with $V$. cholerae cells in the absence of an 176 intermediary host factor (Fig. 2D).

177 Some host lectins can promote the agglutination of target cells $(42,44,45)$. For example, SP-

178 D leads to agglutination of the fungal pathogen Pneumocystis carinii (jiroveci) (38) and the

179 bacterial pathogen Streptococcus pneumoniae (42). Incubation of $V$. cholerae cells with human

180 SP-D in vitro also led to their agglutination, indicating that SP-D binding can alter $V$. cholerae

181 physiology (Fig. 2E, wide field in Fig. S2B). We next used the well-established suckling mouse

182 model of cholera to investigate if SP-D impacts $V$. cholerae intestinal colonization. For these

183 experiments, heterozygous $\left(s f t p d^{+/}\right)$breeders were used to generate litters that contained both 
$184 s f t p d^{+/+} / s f t p d^{-/+}\left(\mathrm{SP}_{-} \mathrm{D}^{+}\right)$and $\left.s f t p d^{-/}\left(\mathrm{SP}^{-}\right)^{-}\right)$offspring. Littermates of suckling mice were

185 inoculated with WT $V$. cholerae and bacterial burdens in the proximal and distal small intestine

186 were enumerated $18 \mathrm{hrs}$ after inoculation (Fig. 2F). There were significantly higher V. cholerae

187 burdens in proximal small intestinal samples from SP-D ${ }^{-}$vs SP-D ${ }^{+}$mice, suggesting that SP-D

188 contributes to intestinal defense. In contrast, there was no difference in the number of $V$.

189 cholerae recovered from the distal small intestines of SP-D ${ }^{-}$and SP-D ${ }^{+}$mice. Thus, SP-D's

190 protective function appears to be limited to the proximal small intestine.

Identification of $V$. cholerae and host proteins on the pathogen cell surface during infection

The observation that a host protein SP-D, is bound to the $V$. cholerae cell surface during

infection led us to hypothesize that additional host proteins are also present at this pathogen-host

define how viral or parasitic infection leads to changes in the landscape of the surface proteome

197 of eukaryotic cells $(5,6,46-48)$. To identify both bacterial- and host-derived proteins present at

198 the surface of $V$. cholerae cells collected from infected animals, we developed $\underline{\text { Surface }}$ Protein

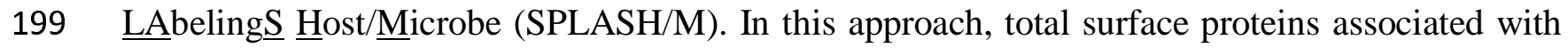

$200 V$. cholerae cells isolated from the diarrheal fluid of infected rabbits were first labeled with the

201 cell-impermeable primary amine biotinylation reagent Sulfo-NHS-SS-Biotin (Fig. 3A). After

202 labeling, bacterial outer membrane fractions were purified and subjected to affinity purification

203 to isolate biotinylated proteins. Then, TMT-based mass spectrometry was used to identify and

204 quantify the labelled proteins. The biotinylated fraction contained the known outer membrane

205 protein OmpU, but not the cytoplasmic RNA polymerase subunit RpoB, confirming that the

206 bacterial lysis protocol did not lead to cytoplasmic contamination of the biotinylated fractions 
207 (Fig. S3A-C). Critically, host proteins bound to the $V$. cholerae cell surface as well as bacterial

208 surface proteins were labeled using this protocol, and detected peptides were mapped to both the

$209 V$. cholerae and the rabbit genomes.

210 To contextualize the host proteins found in the biotinylated fractions, we also performed

211 TMT-MS analysis on cell-free fractions of the diarrheal fluid, from which bacteria, particulate

212 matter, and host cells had been removed by filtration. After removing proteins for which only 1

213 peptide was found, we identified 564 total proteins, including 382 rabbit and 182 bacterial

214 proteins, across all conditions (Table S3). Hierarchical clustering revealed that the proteins

215 identified in the three surface labeled samples and the three diarrheal fluid samples clustered

216 together and exhibited distinct proteomic profiles (Fig. 3B). As expected, the abundance of most

217 rabbit proteins was greater in the fluid samples, except for a small subset of $\sim 35$ proteins that

218 were more abundant in the surface labeled samples (Fig. 3B). Similarly, a subset of $\sim 50 \mathrm{~V}$.

219 cholerae proteins was more abundant in the fluid samples (Fig. 3B). Notably, these proteins

220 included CT, Xds (VC2621), a secreted nuclease involved in mediating escape from neutrophil

221 extracellular traps and in degradation of extracellular DNA (49) and PrtV, a metalloprotease

222 implicated in $V$. cholerae virulence (50). Several $V$. cholerae cell surface-associated virulence

223 factors known to be up-regulated in vivo (25), such as TCP components, HutA, an outer

224 membrane heme receptor (51), and the accessory colonization factor AcfA, required for efficient

225 intestinal colonization (52) and present in the outer membrane vesicles (OMVs) V. cholerae

226 produces in vivo (31) were included in the surface labelled samples, providing further biological

227 validation to the dataset. Bioinformatic predictions of protein subcellular localization revealed

228 that $38 \%$ of the surface-labeled V. cholerae proteins were outer membrane proteins (Fig. 3C),

229 constituting $\sim 32 \%$ of the total predicted $V$. cholerae outer membrane proteome. In contrast, only 
$2.7 \%$ of the total predicted $V$. cholerae cytosolic proteome were labeled, reinforcing the idea that

231 there was minimal cytoplasmic contamination in the labeled samples. CT was one of the surface-

232 labeled proteins, suggesting that a fraction of CT remains associated with the cell surface prior to

233 its secretion. Notably, $46 \%$ of the proteins previously identified in $V$. cholerae OMVs released

234 during infection (31) were identified in the surface-labeled proteome (Fig. S3C), consistent with

235 the idea that OMVs contain a subset of surface-associated proteins.

The most intriguing set of proteins identified with SPLASH/M were the 36 rabbit proteins

237 that were enriched on the $V$. cholerae surface compared to diarrheal fluid (Fig. 3D). One of these

238 HBBP was Intelectin, a lectin previously found to be associated with $V$. cholerae during

239 infection (32) and another was SP-D, which was shown to bind V. cholerae above (Fig. 2). Some

240 of the HBBPs (8/36), like SP-D, are proteins with known or predicted roles in host defense and

241 inflammation; however, most of these proteins are thought to function in pathways that are not

242 directly related to host defense and are not known to associate with bacterial cells.

\section{LPO, Annexin A1, and ZAG directly bind $V$. cholerae}

245 Three of the identified HBBPs, Lactoperoxidase (LPO), Annexin A1 (AnxA1), and Zinc-

246 alpha-2-glycoprotein (ZAG, or AZGP1) were chosen for further study. Although each of these

247 proteins has been reported to be in the extracellular space, none have been shown to bind

248 bacteria. LPO and AnxA1 have been implicated in innate defense (53-55). LPO generates the

249 antimicrobial hypothiocyanite in presence of $\mathrm{H}_{2} \mathrm{O}_{2}$, and is expressed in secretions including milk

250 and saliva and on mucosal surfaces including the intestinal epithelium $(55,56)$. Annexin A1 is

251 generally thought of as a host cell surface death marker (57), and $V$. cholerae proteases have

252 been found to modulate its abundance in the intestines of infected rabbits (32). ZAG is a soluble 
253 protein present in serum and other body fluids that has been associated with diverse non-immune

254 functions (58,59). Notably, however, ZAG exhibits a major histocompatibility complex (MHC)

255 like-structure and exhibits structural similarities to beta-2-microglobulin (B2M) (60,61).

256 To corroborate the proteomic data, we first probed $V$. cholerae samples isolated directly

257 from the diarrheal fluid of infected rabbits for the presence of LPO, AnxA1 and ZAG by

258 Western blotting. Bands corresponding to each protein were detected on the bacterial cells

259 collected from infected animals, suggesting that LPO, AnxA1 and ZAG associate with $V$.

260 cholerae cells during infection (Fig. 4A-C).

261 Next, we tested if these proteins directly interact with $V$. cholerae grown in the laboratory

262 using the binding assay described above (Fig. 4D-F). For all three proteins, a band corresponding

263 to the molecular weight of the respective purified protein was detected in the elution fraction,

264 though the amount of ZAG bound was not as great as the other two proteins. Little or no protein

265 was observed in the wash fractions for any of these proteins, suggesting that each protein can

266 interact with $V$. cholerae in the absence of additional host factors (Fig. 4D-F). Apparent

267 proteolysis of Annexin A1 was detected in the in vivo as well as in vitro assays consistent with

268 the previous report that $V$. cholerae proteases can cleave Annexin A1 (Fig. 4B, Fig. 4E, see star 269 Ref).

270 We reasoned that the capacity of LPO, AnxA1 and ZAG to bind microbes was not likely

271 to be restricted to $V$. cholerae and hypothesized that these HBBPs may bind to conserved

272 microbial cell surface structures such as glycans or phospholipids. To test whether these three

273 proteins bind to microbial glycans, we used the glycan microarrays developed by the Consortium

274 for Functional Glycomics (CFG; http://www.functionalglycomics.org/). These microarrays

275 contain more than 300 highly purified and characterized bacterial polysaccharides isolated from 
276 a broad range of diverse microbes (62), but do not include $V$. cholerae polysaccharides. In these

277 experiments, two doses (5 and $50 \mu \mathrm{g} / \mathrm{ml})$ of each HBBP were put on the arrays and after

278 incubation, were washed, and binding was detected with a fluorescent secondary antibody; the

279 signal measured with the secondary antibody alone was used to set background levels of

280 detection (Fig. 4GH, and S4 A-B). Both ZAG and LPO exhibited dose-dependent binding signals

281 to different polysaccharides, whereas AnxA1 did not (Fig. 4GH, and S4 A-B). ZAG bound to

282 Salmonella and Shigella boydii LPS and the capsular polysaccharide from S. pneumoniae 34

283 (Fig. 4G, top 5 hits). LPO bound to polysaccharides from different microbes, including $A$.

284 methanolieus, and Klebsiella (Fig. 4H, top 5 hits). Together, these data suggest that although

285 ZAG and LPO are not considered lectins, they can bind to structurally diverse microbial glycans.

287 HBBPs interact with gut commensal bacteria

Given the binding of LPO and ZAG to bacterial glycans, we hypothesized that these

289 HBBPs, as well as AnxA1, may also bind to symbiotic organisms within the gut microbiota.

290 Consistent with this idea, a previous study found that SP-D bound to 2\% of fecal bacteria (39).

291 We developed a modified 'IgA-Seq'-like method (63) to isolate and identify symbiotic microbes

292 that are bound by LPO, AnxA1 or ZAG in the intestine (Fig. 5A). Microorganisms were isolated

293 from the feces of specific-pathogen-free (SPF) mice and labeled with the DNA-specific dye

294 SybrGreen, to facilitate differentiation of living microbes from food debris. HBBP-coated

295 microorganisms were detected by flow cytometry, using biotinylated anti-HBBP antibodies and

296 Cy7-conjugated streptavidin (Fig. 5A). While almost no bacteria were labeled by the Cy7-

297 strepavidin secondary reagent, antibodies to LPO, AnxA1 or ZAG, were found to bind to 1-10\%

298 of the fecal microbiota in SPF mice. LPO coated a somewhat higher fraction of microbes $(6.5 \%$ 
$299 \pm 3)$ than Annexin A1 $(3 \% \pm 2)$, and ZAG $(2 \% \pm 3$; Fig. 5A-B). Thus, these 3 HBBP, like IgA 300 and SP-D, interact with gut symbionts.

302 FACS to sort the HBBP-bound (and hence fluorescently tagged) and unbound bacterial fractions

303 in each sample, and then carried out $16 \mathrm{~S}$ rRNA sequencing analysis to classify the populations

304 (Fig. 5C). PCA showed that the positive (HBBP-coated) and negative (unbound) populations for 305 each HBBP were distinct (Fig. S5A). The uncoated bacteria from all three analyses generally 306 clustered together, whereas the LPO-, AnxA1-, and ZAG-coated bacteria formed distinct 307 clusters, suggesting that these HBBPs bind to distinct microbial species. Accordingly, 308 operational taxonomic unit (OTU) distributions between coated and uncoated populations 309 differed; the coated bacteria were enriched for different OTUs for all three of these proteins (Fig. 310 5D). In particular, 1) LPO-coated bacteria were enriched in Lactobacillaceae, Turicibacteraceae

311 and Coriobacteriaceae; 2) ZAG-coated bacteria were enriched in Lachnospiraceae, 312 Ruminococcaceae and Turicibacteraceae; and 3) Annexin A1-coated bacteria were highly 313 enriched in Lactobacillaceae. These data suggest that these 3 proteins interact with

314 taxonomically distinct microbes.

316 Discussion

317 Despite more than a century of research on cholera pathogenesis (64) there is limited 318 knowledge of the protein content of choleric diarrheal fluid, and of the proteomic landscape of 319 the $V$. cholerae cell surface-host interface during infection. Using the infant rabbit model of 320 cholera, we unexpectedly discovered that CT, V. cholerae's signature virulence factor, is almost 321 solely responsible for the pathogen's impact on the host's secretion or release of proteins during 
322 infection. SP-D, one of the most abundant proteins in diarrheal fluid, was found to be associated

323 with the $V$. cholerae surface during infection and to impede $V$. cholerae colonization in the

324 proximal small intestine. We developed SPLASH/M, to chart the protein landscape of both

325 bacterial and additional host proteins present at the pathogen surface during infection. 36 host-

326 derived bacterial binding proteins (HBBP) were identified with this approach. Additional studies

327 of three of these proteins, LPO, AnxA1, and ZAG, corroborated their capacity to bind $V$.

328 cholerae and demonstrated that LPO and ZAG can bind to bacterial glycans. Moreover, these

329 proteins were found bound to distinct symbiotic bacteria in the gut microbiota, suggesting that

330 HBBPs may modulate the composition and function of host-associated microbial communities.

331 These observations suggest that approaches to define the proteins present at the microbial

332 surface-host interface, such as SPLASH/M, will provide a valuable new tool for understanding

333 microbe-host interactions.

334 Cholera toxin's primary role in $V$. cholerae pathogenesis is generally thought to be in 335 facilitating pathogen dissemination and transmission by dramatically increasing the volume of

336 diarrhea in infected individuals. In experimental animals, CT only has marginal impacts on $V$.

337 cholerae intestinal colonization burden per se $(35,65)$, but since there are massive numbers of the

338 pathogen shed in diarrheal stool, the toxin has a major net impact on pathogen replication and

339 dissemination. Furthermore, recent studies suggest that CT impacts the nutrient composition of

340 the intestinal milieu in infected animals, potentially supporting optimal in vivo V. cholerae

341 replication/ colonization. Besides stimulating secretion of $\mathrm{Cl}^{-}$and water into the intestinal lumen,

342 CT is also known to exert additional effects on intestinal epithelial cells, including goblet cell

343 degranulation, leading to mucus secretion $(24,66,67)$. It is possible that at a subset of the $\sim 1000$

344 CT-dependent host proteins found in diarrheal fluid are released from goblet cell granules along 
with the mucins that constitute the intestinal mucus layer. Our data also suggest that CT not only

346 stimulates secretion or release of host proteins into the lumen, but that this potent toxin also

347 impedes release of host factors. Several proteins belonging to protease inhibitor families were

348 less abundant in both WT infection and after CT administration compared to V. cholerae $\Delta$ ctx

349 infection (Fig S1). Thus, CT may increase the abundance of intestinal proteases, modifying

350 proteolytic outcomes and thus the proteomic composition of choleric diarrhea.

351 The consequences of CT modulation of host factors implicated in innate defense, particularly

352 on V. cholerae's growth and survival in the intestinal niche, require further study. SP-D, one of

353 the CT-dependent host factors we identified, was found to be a novel intestinal mucosal defense

354 factor. This C-type lectin binds to L-glycero-D-mannoheptose (Hep), a constituent of the

355 partially conserved lipopolysaccharide (LPS) inner core of many Gram-negative bacteria,

356 including $V$. cholerae (43). SP-D was associated with the $V$. cholerae cell surface during

357 infection and led to $V$. cholerae aggregation in vitro. Comparisons of $V$. cholerae growth in

$358 s f t p d^{+/+}$and $s f t p d^{-/}$infant mice, showed that SP-D protects against $V$. cholerae colonization,

359 providing a new role for this lectin that has been linked to pulmonary defense against fungal,

360 viral and bacterial pathogens (42,44,68,69). Strikingly, protection afforded by SP-D against $V$.

361 cholerae colonization appeared to be restricted to the proximal portion of the small intestine. We

362 previously observed a similar localized phenotype for $V$. cholerae colonization in infant mice

363 lacking D-amino acid oxidase (DAO) (70), and propose that these observations reveal regional

364 specificity to small intestinal mucosal defense factors. Although it seems paradoxical that $V$.

365 cholerae would stimulate release of a factor such as SP-D that inhibits its own colonization, this

366 may instead reflect the massive net gain that CT provides $V$. cholerae with respect to

367 transmission. Thus, even if CT induces SP-D as part of a host defense program, V. cholerae still 
368 benefits from the toxin's presence. It remains to be seen whether other enteric pathogens,

369 including those that rely on secreted toxins for pathogenesis, also induce SP-D release, and

370 whether this release is beneficial or antagonistic to the pathogen.

371 By honing our proteomic approach with SPLASH/M, we revealed the in vivo V. cholerae

372 surface proteome as well as the complement of host proteins bound to the pathogen's surface.

373 Among the most abundant bacterial surface proteins during infection were TcpA and a methyl-

374 accepting chemotaxis (VCA0176), two V. cholerae proteins that are known to be immunogenic

375 (71), suggesting SPLASH/M-defined bacterial proteins represent antigenic targets that may be of

376 therapeutic use.

377 SPLASH/M also enabled the unbiased identification of a class of host proteins we termed

378 host-derived bacterial binding proteins (HBBPs) that were more abundant on the V. cholerae

379 surface than in diarrheal fluid. This included Intelectin, which is known V. cholerae- targeting

380 HBBPs implicated in microbial recognition that were identified with different methods $(32,72)$.

381 Only $\sim 25 \%$ of the identified HBBPs have previously been linked to host defense/ inflammation.

382 Most of the other HBBPs were classified as enzymes or linked to metabolism, raising the

383 possibility that these factors might impact the in vivo physiology of $V$. cholerae and other

384 microbes through binding; alternatively, the apparent binding of some of these factors to the $V$.

385 cholerae surface could be fortuitous.

386 Three HBBP chosen for additional analysis, AnxA1, LPO and ZAG, bound to V. cholerae

387 cells grown in laboratory media without additional host factors present (Fig. 4), providing

388 evidence that they can directly bind the pathogen. Although only ZAG and LPO bound to

389 specific and distinct microbial glycans, since AnxA1 belongs to the annexin superfamily of

390 calcium-dependent phospholipid-binding-proteins, it may instead bind a non-carbohydrate ligand 
on the bacterial cell surface, such as phosphatidylserine (PS), a lipid constituent of the bacterial

392 membrane (54). We found that $1-10 \%$ of fecal microbiota were bound by AnxA1, ZAG and

393 LPO, a similar range as reported for IgA and SP-D $(39,63)$. Each of these 3 proteins bound to

394 distinct microbial taxa, raising the possibilities that these proteins and other HBBPs might play a

395 role in general host microbial surveillance and modify the composition and/or function of the

396 intestinal microbiome. These SPLASH/M-identified interactions may not necessarily be

397 antagonistic, and could have important and far-reaching consequences on host physiology. For

398 example, mice deficient in SP-D have distinct gut microbiota and immune profiles (39).

399 While our use of the infant rabbit model of cholera facilitated the development of

400 SPLASH/M, this approach should be applicable to additional pathogenic and non-pathogenic

401 microbes alike. Methods to isolate particular microorganisms, such as FACS, will facilitate

402 SPLASH/M-based definitions of the in vivo proteomic landscapes of microbe-host interfaces.

403 Furthermore, variants of this approach should be applicable to reveal this interface for microbes

404 that grow intracellularly (6-9). Additional efforts to reveal the full complement of HBBPs during

405 infection with different pathogens in different tissues as well as their functions will reveal

406 valuable new insights into microbial and host biology. Moreover, since gut symbionts are

407 intrinsically linked to host physiology and health, investigation of HBBP coating of symbionts in

408 different contexts, such as obesity, will offer new perspectives in pathophysiology. Ultimately,

409 defining the proteomic composition of the microbe-host interface will deepen our understanding

410 of interkingdom interactions that underlie homeostasis and disease, and offer new factors to

411 target for therapeutic applications.

412

\section{Acknowledgments}


415 for expert help with bioinformatics. Sharon Prentice for technical assistance and the Bettencourt-

416 Schueller foundation for support. Glycomic experiments were done with the participation of the

417 Protein-Glycan Interaction Resource of the CFG, and the National Center for Functional

418 Glycomics, supporting grant P41 GM103694 and R24 GM137763. We thank the ThermoFisher

419 Center for Multiplexed proteomics of Harvard Medical School for isobaric tandem mass tag

420 proteomic. Work in M.K.W laboratory is supported by HHMI and NIH grant R01 AI-042347.

421 T.Z. was supported by a Sarah Elizabeth O'Brien Trust Postdoctoral Fellowship. A.Z. was

422 supported by an EMBO long-term fellowship (ALTF 1514-2016) and by a HHMI Fellowship of

423 the Life Sciences Research Foundation.

424

425 Declaration of interests

426 The authors declare no competing interests.

427

\section{Authors contribution}

429 A.Z. and M.K.W. conceived and designed the study. A.Z., H.Z., B.F., and C.J.K, performed all 430 experiments; A.Z. and R.T.G., analyzed data. A.Z. and M.K.W. wrote the manuscript and all 431 authors edited the paper. 
440 Figure 1: The diarrheal fluid proteome in infant rabbits is largely stimulated by CT.

441 (A) Schematic of the experimental protocol for identification of the proteome in diarrheal fluid

442 isolated from rabbits inoculated with $V$. cholerae, $V$. cholerae $\Delta c t x$, purified cholera toxin (CT) 443 or buffer alone (Mock).

444 (B-C) Hierarchical clustering and principal component analysis (PCA) of proteomes identified

445 by TMT-based mass spectrometry. (B) Heatmap is sorted by the log2 fold change between WT $446 \quad$ V. cholerae infected and mock.

447 (D) Scatterplot showing relative fold changes in the abundance of proteins isolated from rabbits 448 inoculated with either wild-type $V$. cholerae $(\mathrm{Vc})$ or purified cholera toxin $(\mathrm{CT})$, each relative to 449 the proteomes of control animals. The red dot indicates SP-D.

450 (E) Comparison of the gene sets enrichment from the GO molecular function pathways for the

451 proteomes of rabbits infected with $V$. cholerae, V. cholerae $\Delta c t x$, or CT infected rabbit versus

452 control animals. NES: normalized enrichment score. Pathways were considered to be 453 significantly enriched if the adjusted p-value was less than 0.25.

\section{Figure 2: SP-D is an intestinal mucosal defense factor}

456 (A) Detection of SP-D in filtered diarrheal fluid by immunoblotting. Diarrheal fluids were

457 collected, filtered and TCA precipitated before western blotting using anti-SP-D antibody.

458 (B) Detection of SP-D associated with $V$. cholerae cells isolated from diarrheal fluid. 
459 (C) Immunofluorescence micrographs of rabbit small intestines inoculated with $V$. cholerae-

460 GFP. Bacterial cells were detected by GFP fluorescence, SP-D was detected with a goat anti-SP-

461 D antibody followed by anti-goat antibody coupled to Alexa fluor 468. Phalloidin (for actin

462 labeling) is stained with an antibody coupled to Alexa fluor 647 and DAPI (for DNA labeling) is

463 shown is blue. Scale bar is $100 \mu \mathrm{m}$.

464 (D) Immunoblot detection of recombinant SP-D incubated with $V$. cholerae cells grown in LB.

465 From left to right: purified SP-D protein, flowthrough (unbound protein), washes and bound

466 fraction were analyzed alongside with bacterial cells treated with buffer only (mock).

467 (E) SP-D aggregates V. cholerae cells. Bacterial cells were incubated in PBS containing 5mM

$468 \mathrm{CaCl}_{2}$ for 1 hour in the presence (lower panel) or absence (upper panel) of SP-D (10 $\left.\mu \mathrm{g} / \mathrm{ml}\right)$ and

469 analyzed by light microscopy. Scale bar is $10 \mu \mathrm{m}$. Results from an experiment representative of

470 three independent experiments are shown.

471 (F) V. cholerae small intestinal colonization in littermate $s f t p d 广$ and $s f t p d^{+} \digamma^{+}$mice. Bacterial 472 burdens recovered from proximal and distal small intestine 18 hrs after $V$. cholerae inoculation.

473 Note S-PD+ include both heterozygotes $\left(s f t d^{+} \digamma\right)$ and homozygous $\left(s f t d^{+} \digamma^{+}\right)$animals.

475 Figure 3: Identification of surface-exposed $V$. cholerae proteins and $V$. cholerae-bound 476 host-derived proteins

477 (A) Schematic of the SPLASH/M protocol.

478 (B) Hierarchical clustering of the surface proteins identified by SLASH/M and the proteins 479 identified in diarrheal fluid in three animals. Host-derived and bacterial proteins were sorted 480 separately by $\log 2$ fold change prior to clustering. 
481 (C) Proportion of the proteins identified by SPLASH/M relative to total number of ORFs

482 encoded in the $V$. cholerae genome for each predicted localization (extracellular (E), outer

483 membrane (OM), periplasmic (P), inner membrane (IM) or cytoplasmic (C)).

484 (D) Heat map showing the ratio of abundance of host-binding bacterial proteins (HBBPs)

485 identified with SPLASH/M versus their abundance in the diarrheal fluid of the corresponding

486 animal.

487

Figure 4: LPO, AnxA1 and ZAG interact with V. cholerae

489 (A-C) Detection of LPO, AnxA1 and ZAG associated with $V$. cholerae cells in the intestine. $V$. 490 cholerae cells collected from diarrheal fluid of infected rabbits were washed twice and lysed.

491 Proteins were separated by $10 \%$ acrylamide SDS-PAGE and immunoblots for LPO (A), AnxA1

492 (B) and ZAG (C) were performed.

493 (D-F) Detection of LPO, AnxA1 and ZAG associated with $V$. cholerae cells grown in the 494 laboratory. Immunoblot detection of recombinant LPO (D), AnxA1 (E) and ZAG (F) incubated 495 with $V$. cholerae cells cultured in LB. From left to right: purified proteins, flowthrough (unbound 496 protein), washes and bound fraction were analyzed alongside with bacterial cells treated with 497 buffer only (mock).

498 (G-H) ZAG and LPO glycan binding assessed by glycan microarrays. Binding of recombinant 499 human ZAG $(5 \mu \mathrm{g} / \mathrm{ml}$ and $50 \mu \mathrm{g} / \mathrm{ml})(\mathrm{G})$ and LPO $(5 \mu \mathrm{g} / \mathrm{ml}$ and $50 \mu \mathrm{g} / \mathrm{ml})$ (H) to microbial 500 glycan arrays. Data are shown as mean \pm s.d. $(n=4$ technical replicates). (Glycan array data 501 organized by genus are in Supplemental Fig. S4 and the full dataset in Supplemental Table S4) 
504 (A) Schematic of the workflow for detection of HBBP bound to fecal microbiota.

505 (B) Flow cytometry of microbiota stained with Streptavidin-PE-Cy7 only, or antibodies to ZAG,

506 LPO or AnxA1.

507 (C) Quantification of flow cytometry data from (B).

508 (D) Relative abundance of order or family-specific taxonomic units (OTUs) after 16s rRNA

509 sequencing of sorted cells from (A). The bound (positive) and unbound (negative) fraction of the 510 microbiota is shown. Each bar represents the average from four individual mice.

512 Figure S1: Diarrheal fluid proteomic response to V. cholerae is largely driven by CT.

513 (A) Bacterial burdens recovered from diarrheal fluid harvested from $V$. cholerae and $V$. cholerae $514 \Delta c t x$ infected rabbits.

515 (B) Diarrheal fluid volumes collected from rabbits infected with $V$. cholerae, $V$. cholerae $\Delta$ ctx, 516 purified cholera toxin (CT) and buffer (Mock).

517 (C) Predicted localization of rabbit proteins identified in diarrheal fluid. Bioinformatic analysis 518 was performed using the G:Profiler (http://biit.cs.ut.ee/gprofiler/) webtool for finding enriched

519 GOcatgories.

520 (D) Scatterplot of relative fold changes in protein abundances isolated from rabbit infected with $521 V$. cholerae $\Delta c t x$ (Delta) compared to wild-type $V$. cholerae (Vc), each relative to the proteomes 522 of mock infected animals. The red dot indicates SP-D.

524 Figure S2: SP-D is an intestinal mucosal defense factor

525 (A) Immunofluorescence micrographs of rabbit small intestines inoculated with GFP-expressing $526 V$. cholerae. Bacterial cells were detected by GFP fluorescence. Phalloidin (for actin labeling) is 
527 stained with an antibody coupled to Alexa fluor 647 and DAPI (for DNA labeling) is shown is

528 blue. Only anti-goat antibody coupled to Alexa fluor 468 was used to assess unspecific staining

529 of the second antibody. Scale bar is $100 \mu \mathrm{m}$.

530 (B) Wide field of micrographs shown in Fig. 2C. Scale bar is $10 \mu \mathrm{m}$.

531

532 Figure S3: Identification of surface-exposed $V$. cholerae proteins and $V$. cholerae-bound

533 host-derived proteins

534 Controls validating surface biotinylation for SPLASH/M (A-C). Proteins isolated following

535 SLASH/M protocol with (+) or without (-) the biotinylation step were separated by $10 \%$

536 acrylamide SDS-PAGE and silver-stained (A). Presence of cytoplasmic RNA polymerase $\beta$ (B)

537 and outer-membrane OmpU (C) were assessed by immunostaining with anti-RNApol and anti-

538 OmpU antibodies, respectively. T: total V. cholerae lysate.

539 (D) Venn diagram showing the comparison of $V$. cholerae proteins identified with SLASH/M

540 and $V$. cholerae outer membrane vesicles (OMV's) proteomes; 181 and 110 are the total number

541 of proteins from each group (31).

543 Figure S4: LPO, AnxA1 and ZAG binding to microbial glycans.

544 (A-C) Results of ZAG (A), LPO (B) and AnxA1 (C) binding to Microbial Glycan Microarray

545 organized by genus and species. Data are presented as the mean \pm s.d. ( $\mathrm{n}=4$ of a technical

546 replicate for each immobilized glycan). Note: scales on $\mathrm{Y}$ axes are different. The complete

547 datasets are available in Supplementary Table S4. 
550 (A) Principle coordinate analyzes based on the Bray Curtis $\beta$-diversity metric showing that

551 samples for each AnxA1, LPO or ZAG positive population cluster together while all the HBBP

552 negative populations cluster together.

553 (B) Alpha rarefaction plot. Shown are the number of different observed features as a function of 554 the number of sequences analyzed and generated with QIIME2. 


\section{Materials and Methods}

\section{7}

\section{Ethics Statement}

559 Animal experiments were conducted according to protocols approved by the Brigham and

560 Women's Hospital Committee on Animals (Institutional Animal Care and Use Committee

561 protocol number 2016N000334 and Animal Welfare Assurance of Compliance number A4752-

562 01) and in accordance with recommendations in the National Institute of Health's Guide for the

563 Care and Use of Laboratory Animals and the Animal Welfare Act of the United States

564 Department of Agriculture.

565

566 Bacterial strains, and growth condition

$567 V$. cholerae strain H1, a clinical isolate from 2010 and its $\Delta c t x$ derivative $(34,65)$ were cultured

568 in Luria-Bertani (LB) medium or on LB agar plates at $37^{\circ} \mathrm{C}$ unless otherwise stated, 569 supplemented with streptomycin at a concentration of $200 \mu \mathrm{g} / \mathrm{ml}$. V. cholerae cells carrying the 570 pUA-GFP plasmid, which contains a GFP gene under strong constitutive promoter) (73) was

571 used for immunostaining of infected infant rabbit small intestine and cultured overnight at $30^{\circ} \mathrm{C}$

572 in LB supplemented with streptomycin $(200 \mu \mathrm{g} / \mathrm{ml})$ and kanamycin $(50 \mu \mathrm{g} / \mathrm{ml})$.

573

574 Infant rabbit infection studies

575 For inocula preparation, overnight bacterial cultures were diluted 1:100 in $50 \mathrm{~mL}$ LB and

576 cultured with aeration at $37^{\circ} \mathrm{C}$ until OD600 0.5-0.9. $\sim 2 \times 10^{10} \mathrm{CFU}$ were pelleted by

577 centrifugation at $5000 \mathrm{~g}$ for $5 \mathrm{~min}$, the supernatant was removed, and cell pellets were re-

578 suspended in $10 \mathrm{~mL}$ of $2.5 \%$ sodium bicarbonate solution $(2.5 \mathrm{~g}$ in $100 \mathrm{~mL}$ water; $\mathrm{pH} 9.0)$ to a 
579 final cell density of $\sim 2 \times 10^{9} \mathrm{CFU} / \mathrm{ml}$. Serial dilutions of the inoculum were plated to enumerate

580 the inoculum dose. Infant rabbit infections were performed as previously described $(24,28)$.

581 Briefly, two-day old litters of mixed gender New Zealand White rabbit were co-housed with a

582 lactating dam (Charles River) for the duration of the experiment. Each infant rabbit was

583 orogastrically inoculated with $500 \mu \mathrm{l}$ of the inoculum, using a size 4 French catheter. Following

584 inoculation, the infant rabbits were monitored at least $2 x /$ day for signs of illness and euthanized

$585 \sim 16-18$ hours post infection. For purified cholera toxin (CT) experiments, $50 \mu \mathrm{g}$ CT (Sigma,

586 C8052) was used per rabbit $(500 \mu \mathrm{l}$ of a $100 \mu \mathrm{g} / \mathrm{ml}$ solution in sodium bicarbonate). Animals

587 infected with CT were euthanized 3-6 h post-inoculation.

\section{Mice colonization assay}

$590 \mathrm{C} 57 \mathrm{BL} / 6 \mathrm{Sftpd}^{\top} /$ mice were purchased from Jackson laboratory and were bred at the Harvard

591 Institutes of Medicine animal facility. Littermates that were the offspring of heterozygous

$592 \mathrm{Sftpd}^{+} /$breeders were used in this study. Infant mice were genotyped post-mortem at the end of

593 the colonization assay. Intestinal colonization in infant mice was conducted as described (74).

594 Briefly, bacterial cells were grown overnight at $30^{\circ} \mathrm{C}$ and then diluted 1:1000 in LB. Infant mice

595 were orogastrically inoculated with $50 \mu \mathrm{l}\left(\sim 10^{5} \mathrm{cfu}\right)$ and then sacrificed after $\sim 18$ hours. Small

596 intestines were equally divided into proximal and distal segments. Dilutions of small intestines

597 homogenates were plated on LB agar plates supplemented with $200 \mu \mathrm{g} / \mathrm{ml}$ streptomycin to

598 enumerate CFU. Statistical significance was determined using a Mann-Whitney U t test. Infant

599 mice were genotyped post-mortem at the end of the colonization assay using tail chips and PCR

600 according to Jackson laboratory protocol using primers 24516 (TGT TGA TGC ATG TTA TGT 
602 TGG GAA AAG CG).

\section{Immunofluorescence microscopy}

605 Immunofluorescence images were analyzed from 6 rabbits infected with $V$. cholerae-GFP; 2 or 3

606 sections of the small intestine per rabbit were examined. Briefly, tissue samples used for 607 immunofluorescence were fixed in 4\% PFA for 2 hours, and subsequently stored in $30 \%$ sucrose

608 prior to embedding in a 1:2.5 mixture of OCT (Tissue-Tek) and stored at $-80^{\circ} \mathrm{C}$, as previously 609 described (75). Frozen sections were then cut at a thickness of $10-15 \square \mu \mathrm{m}$ using a cryotome 610 (catalog no. CM1860UV; Leica). Sections were first blocked with 5\% bovine serum albumin 611 (BSA) in PBS for $1 \square \mathrm{h}$ and then stained overnight at $4{ }^{\circ} \mathrm{C}$ with a primary anti-SP-D antibody 612 (1:500, R\&D Systems, AF1920), diluted in PBS with 0.5\% BSA and 0.5\% Triton X-100, anti613 GFP labeled with Alexa 488 (1/1,000, SAB4600051). After washing 3x with 1× PBS containing $6140.5 \%$ Triton X-100, sections were incubated with Alexa Fluor 647 phalloidin (1/1000; 615 Invitrogen) and anti-Goat Alexa Fluor 568 (1/1000, ThermoFisher, A-11055) for $1 \square \mathrm{h}$ at room 616 temperature, washed, and stained for $5 \square \min$ with 4',6-diamidino-2-phenylindole (DAPI) at $6172 \square \mu \mathrm{g} / \mathrm{ml}$ for $10 \square \mathrm{min}$, and covered with ProLong Diamond mounting medium. Following 618 staining, slides were imaged using a Nikon Ti Eclipse equipped with a metal-oxide619 semiconductor (sCMOS) camera (Andor Zyla) for wide-field microscopy. 
Diarrheal fluids were filtered through sterile polyester membranes with a pore size of

$6230.22 \mu \mathrm{m}$ before precipitation with trichloroacetic acid (TCA) 15\%, $45 \mathrm{~min}$ on ice. Precipitated

624 proteins were wash once in acetone and resuspended in 1X blue loading buffer (NEB, B7703S).

625 For immunoblotting, bacterial pellets or precipitated proteins were resuspend in blue 626 loading buffer (NEB, B7703S), boiled at $95^{\circ} \mathrm{C}$ for $10 \mathrm{~min}$ and loaded on $10 \%$ gels (Bio-Rad) for

627 electrophoresis. Proteins were transferred from the gel to nitrocellulose membranes and 628 immunoblotted. Antibodies for western blot assays were used at the following concentrations:

629 anti-SP-D (1:2,000, R\&D Systems, AF1920), anti-LPO (1:2000, LSBio, LS2C25068), anti630 AnxA1 (1:500, ThermoFisher, 71-3400), anti-ZAG (1:2000, ThermoFisher, H00000563-B01P), 631 anti-RNA Polymerase (1:2000, Biolegend, 663903) and anti-OmpU (1:500, homemade, gift from 632 the Mekalanos lab). The membranes were developed with SuperSignal West Femto maximum633 sensitivity substrate (ThermoFisher) and visualized with a ChemiDoc Scientific imaging system 634 (BioRad).

\section{Peptide Labeling with Tandem Mass Tags and Mass Spectrometry}

637 Samples were submitted in 1X blue loading buffer (NEB, B7703S) to the Thermo Fisher Center 638 for Multiplexed Proteomics at Harvard Medical School (Boston, MA, USA) for Isobaric Tandem 639 Mass Tag (TMT)-based quantitative proteomics. Briefly, after adjusting proteins to equal 640 concentrations, $40 \mu \mathrm{l}$ of each sample was loaded on $10 \%$ Bis/Tris gels and run at $120 \mathrm{~V}$ for 10

641 min in MES buffer. Gel bands were cut out, destained, reduced and alkylated. In-gel Trypsin 642 digests were performed overnight and peptides were extracted and labeled with TMT10 reagents.

643 Labeling reactions were combined, cleaned, and dried down. Peptides were resuspended in 5\% 644 Acetonitrile, 5\% formic acid and 1/3 of the sample was shot on an Orbitrap Fusion Mass 
645 spectrometer. Peptides were detected (MS1) and quantified (MS3) in the Orbitrap Fusion Mass

646 spectrometer. Peptides were sequenced (MS2) in the ion trap. MS2 spectra were searched using

647 the SEQUEST algorithm against a Uniprot composite database derived from the combined $V$.

648 cholerae and Oryctolagus cuniculus (rabbit) proteomes containing its reversed complement and

649 known contaminants. Peptide spectral matches were filtered to a $1 \%$ false discovery rate (FDR)

650 using the target-decoy strategy combined with linear discriminant analysis. Proteins were

651 quantified only from peptides with a summed signal/noise (SN) threshold of >=200 and MS2

652 isolation specificity of 0.5 .

653

654 Gene set enrichment analysis

655 The G:Profiler (http://biit.cs.ut.ee/gprofiler/) webtool was used for finding enriched GO cellular 656 component terms in the rabbit intestinal proteome. A score above 1.8 for negative log of adjusted 657 p-values was considered significant. Gene set enrichment was performed as previously described 658 (76) using fast GSEA (fGSEA) in R (version 1.8.0) (77) with modifications. Only genes with 659 annotation were considered. The normalized mean proportion for each protein was divided by 660 the value of that protein in the uninfected data set and $\log 2$ transformed to create a fold change. 661 These Log2 fold change values were use as the "rank" for fGSEA.

\section{Hierarchical clustering}

664 The SN of each protein was first normalized by calculating the proportion of the total signal 665 represented by that protein in a given sample. Clustering was then performed on these values in 666 R using heatmap.2 with the default Pearson correlation method. 


\section{In vitro protein- $\mathrm{V}$. cholerae binding assay}

669 Binding assays were carried out as previously described (32). Briefly, bacteria were grown to

670 O.D 0.4 in LB and then centrifuged $(5,000 \mathrm{~g}, 5 \mathrm{~min}$ at RT). Bacterial pellets were washed twice

671 in $25 \mathrm{ml}$ HEPES-buffered saline (140 mM NaCl, $\left.1.5 \mathrm{mM} \mathrm{Na} 2 \mathrm{HPO}_{4}, 50 \mathrm{mM} \mathrm{HEPES}, \mathrm{pH} 7.5\right)$

672 supplemented with $5 \mathrm{mM} \mathrm{CaCl}$. Bacterial cells were then incubated with $0.25 \mu \mathrm{g}$ of purified

673 human SP-D (R\&D Systems, 1920-SP-050), ZAG (R\&D Systems, 4764-ZA-050), AnxA1 (R\&D

674 Systems, 3770-AN-050) or LPO (MyBiosource, MBS954610) for 30 min at RT and washed

675 twice with an equal volume of buffer. Bacterial pellets were then resuspended in 1X blue loading

676 buffer (NEB, B7703S). Unbound input and the two washes were treated with $4 \mathrm{X}$ blue loading

677 buffer (NEB, B7703S) and incubated at $95^{\circ} \mathrm{C}$ for 10 min prior to SDS-PAGE and western blot

678 analysis. All binding experiments were repeated at least 3x with consistent results.

679

680 Bacterial aggregation assay.

$681 V$. cholerae cells were grown to O.D 0.4 in $\mathrm{LB}$, centrifuged $(5,000 \mathrm{~g}, 5 \mathrm{~min}$ at RT) and then

682 resuspended and washed in phosphate-buffered saline (PBS) supplemented with $5 \mathrm{mM} \mathrm{CaCl}_{2}$.

683 Bacterial suspensions were incubated with human SP-D at a concentration of $10 \mathrm{mg} / \mathrm{ml}(\mathrm{R} \& \mathrm{D}$

684 Systems, 1920-SP-050) for $1 \mathrm{~h}$ at RT without agitation and observed by light microscopy (Nikon

685 Ti Eclipse equipped with a metal-oxide-semiconductor (sCMOS) camera (Andor Zyla)). Figures

686 were made using Fiji software (version 2.1.0/1.53c).

688 Surface Protein LAbelingS Host/Microbe (SPLASH/M)

689 Diarrheal fluid was harvested 16-18 hr after inoculation of infant rabbits. The fluid was then

690 filtered through a $5 \mu \mathrm{M}$ filter to remove particulate matter and eukaryotic cells. Bacteria were 
691 isolated from diarrheal fluid by centrifugation $(5000 \times g, 5 \mathrm{~min}$ at RT). Bacterial pellets were

692 washed twice and resuspended in phosphate-buffered saline (PBS) supplemented with $1 \mathrm{mM}$

$693 \mathrm{CaCl}_{2}, 0.5 \mathrm{mM} \mathrm{MgCl} 2$ and $1.5 \mathrm{mM}$ D-biotin at RT. Cell surface biotinylation were performed as

694 described (ref) with modifications. Sulfo-NHS-LC-biotin (ThermoFisher, 21335) was added to a

695 final concentration of $200 \mu \mathrm{M}$ for $20 \mathrm{~min}$ at $\mathrm{RT}$. The reaction was stopped by addition of 2

696 volumes of buffer $(80 \mathrm{mM}$ Tris $\mathrm{pH} 7,100 \mathrm{mM} \mathrm{NaCl}, 30 \mathrm{mM} \mathrm{KCl}, 1 \mathrm{mM} \mathrm{CaCl} 2$ and $0.5 \mathrm{mM}$

$697 \mathrm{MgCl}_{2}$ ). After washing the bacterial cells 3x with the same buffer they were resuspended in 50

$698 \mathrm{mM}$ Tris $\mathrm{pH} \mathrm{7,} 50 \mathrm{mM} \mathrm{NaCl}, 10 \mathrm{mM} \mathrm{MgCl} 2$, DNAse $(0.1 \mathrm{mg} / \mathrm{ml})$, lysozyme $(0.1 \mathrm{mg} / \mathrm{ml})$ and

699 Complete protease inhibitor mixture (Roche). Cells were broken using an Emulsiflex-C3

700 (Avestin) and the crude membrane fraction was isolated by ultracentrifugation at 45,000 $\mathrm{g}$ for 45

701 min. Membrane-containing fractions were washed twice in $50 \mathrm{mM}$ Tris $\mathrm{pH}$ 7, $150 \mathrm{mM} \mathrm{KCl,} 10$

702 mM EDTA and Complete protease inhibitor mixture (Roche). Membranes were then solubilized

703 overnight at $4^{\circ} \mathrm{C}$ in presence of $0.5 \%$ n-Dodecyl $\beta$-D-maltoside (DDM) (Sigma, D4641). Lysates

704 were used for co-immunoprecipitation using Dynabeads M-280 Streptavidin (ThermoFisher,

705 11205D) overnight at $4^{\circ} \mathrm{C}$. Magnetic beads were washed thrice with $1 \mathrm{ml}$ of Tris $\mathrm{pH} 7,100 \mathrm{mM}$

$706 \mathrm{NaCl}$ and $0.2 \%$ Tween 20 and resuspended in $50 \mu \mathrm{L}$ of $1 \mathrm{X}$ blue loading buffer (NEB, B7703S)

707 and heated for $10 \mathrm{~min}$ at $96^{\circ} \mathrm{C}$.

708

709 HHBP binding to glycan arrays

710 Human ZAG (R\&D Systems, 4764-ZA-050), human LPO (MyBiosource, MBS954610) and

711 human AnxA1 (R\&D Systems, 3770-AN-050) were provided to the Protein-Glycan Interaction

712 Resource at the National Center for Functional Glycomics (Beth Israel Deaconess Hospital,

713 Boston) for hybridization to the Microbial Glycan Microarray (MGM). The MGM array were 
714 prepared as previously described (62). The printed array includes polysaccharides derived from

715313 different bacteria printed at $500 \mu \mathrm{g} / \mathrm{ml}$, in replicates of 6 . To interrogate the MGM, ZAG,

716 LPO and AnxA1 were diluted to $5 \mu \mathrm{g} / \mathrm{ml}$ and $50 \mu \mathrm{g} / \mathrm{ml}$ in binding buffer (20 mM Tris-HCl, $\mathrm{pH}$

717 7.4, $150 \mathrm{mM} \mathrm{NaCl}, 2 \mathrm{mM} \mathrm{CaCl}, 2 \mathrm{mM}$ magnesium chloride $\left(\mathrm{MgCl}_{2}\right), 1 \%$ BSA and $0.05 \%$

718 Tween 20) and applied directly to the array surface for $1 \mathrm{~h}$. After incubation, the array was

719 washed by soaking with binding buffer four times. ZAG was detected with Anti-ZAG $(2 \mu \mathrm{g} / \mathrm{ml}$,

720 AZGP1 antibody, H00000563-B01P MaxPab) and anti-mouse IgG-Alexa-488 (5 $\mu \mathrm{g} / \mathrm{ml})$ diluted

721 in binding buffer, applied directly to the array surface and allowed to incubate for $1 \mathrm{~h}$. Similarly,

722 LPO was detected with Anti-LPO $(2 \mu \mathrm{g} / \mathrm{ml}$, Thermofisher PA5-18917) and anti-goat IgG-Alexa-

$723488(5 \mu \mathrm{g} / \mathrm{ml})$ diluted in binding buffer, and then applied directly to the array surface for $1 \mathrm{~h}$.

724 Similarly, AnxA1 was detected with Anti-AnxA1 (2 $\mu \mathrm{g} / \mathrm{ml}$, Sigma, AMAB90558) and anti-

725 mouse IgG-Alexa-488 $(5 \mu \mathrm{g} / \mathrm{ml})$. The arrays were washed in binding buffer (four times), binding

726 buffer without BSA and Tween 20 (four times) followed by deionized water (four times) and

727 scanned. The high and low fluorescence values from the six replicates were eliminated and the

728 remaining four values were averaged. Data were plotted with Excel (Microsoft) as average

729 relative fluorescence units (RFU) versus print identification number. The top 5 HBBP-glycans

730 interactions for ZAG and LPO showed in Fig. 4GH were defined as 3-fold over background and

731 exhibiting a dose-responsive binding which was not the case for AnxA1.

732

\section{Analysis of HBBPs binding microbiota}

734 Fecal pellets from specific pathogen free (SPF) C57BL/6 mice were collected and directly

735 resuspended in phosphate-buffered saline (PBS) (100 mg of feces in $100 \mu \mathrm{l})$ supplemented with

$7361 \% \mathrm{BSA}$ and $1 \mathrm{mM} \mathrm{CaCl}$, and filtered with a $40 \mu \mathrm{m}$ cell strainer to remove particulate matter. 
737 Bacterial suspensions were centrifuged (5,000 g, 5min) and washed twice in the same buffer. 20

$738 \mu \mathrm{l}$ of bacterial suspension was incubated with $2 \mu \mathrm{g}$ of biotinylated anti-LPO (LSBio, LS-

739 C684314), anti-ZAG (R\&D Systems, BAF4764) or anti-AnxA1 (LSBio, LS-C317217) for 30

740 min on ice. After washing 3x and resuspension in PBS, supplemented with 1\% BSA and $1 \mathrm{mM}$

$741 \mathrm{CaCl}_{2}$, bacteria were incubated with $1 \mu \mathrm{g}$ of Streptavidin-PE-Cy7 (ThermoFisher, SA1012) for

$74215 \mathrm{~min}$ on ice. After washing, bacterial genomic DNA was stained with 1/10 000 dilution of

743 SybrGreen followed by two washes. Bacterial suspensions were then analyzed by flow

744 cytometry (Sony, SH800) and HBBP-positive or HBBP-negative population were sorted.

746 16s rRNA gene sequencing and analysis

747 PureLink Microbiome DNA Purification Kit (ThermoFisher, A29790) was used according to the

748 manufacture protocol to extract the DNA from the sorted-microbiota. 16s rRNA amplification

749 were done as previously described (70). Briefly, the V1-V2 region of $16 \mathrm{~S}$ ribosomal RNA was

750 PCR amplified (12.5 ng purified DNA per reaction; Phusion polymerase, New England Biolab)

751 for 25 cycles $\left(95^{\circ} \mathrm{C}\right.$ for $30 \mathrm{~s}, 50^{\circ} \mathrm{C}$ for $30 \mathrm{~s}$ and $72^{\circ} \mathrm{C}$ for $\left.30 \mathrm{~s}\right)$ (primer pair: $27 \mathrm{Fmod} / 338 \mathrm{R}(\mathrm{Ref})$ ).

752 PCR products were then purified (MinElute, QIAGEN) and resuspended in $25 \mu 1$ of $10 \mathrm{mM}$ Tris-

753 $\mathrm{HCl} \mathrm{pH} 8.5$. The V1-V2 PCR products were indexed with the Nextera XT Index kit (Illumina) by

754 PCR (2.5 $\mu$ l PCR product; Nextera XT Index primers; Phusion polymerase) for eight cycles

$755\left(95^{\circ} \mathrm{C}\right.$ for $30 \mathrm{~s}, 55^{\circ} \mathrm{C}$ for $30 \mathrm{~s}$, and $72^{\circ} \mathrm{C}$ for $\left.30 \mathrm{~s}\right)$. The $16 \mathrm{~S}$ rRNA amplicons with indices were

756 purified (MinElute, QIAGEN), resuspended in $25 \mu 1$ of $10 \mathrm{mM}$ Tris- $\mathrm{HCl} \mathrm{pH} 8.5$, quantified with a

757 Qubit 2.0 Fluorometer (Life Technologies), pooled at a concentration of 4nM, denatured, diluted

758 to a final concentration of 4pM and sequenced using the MiSeq Reagent Kit v3 (600-cycle,

759 paired-end, Illumina) on a MiSeq sequencer (Illumina). Sequencing reads were demultiplexed 
760 using MiSeq Reporter v2.0 and further processed using QIIME2 (Ref). Briefly, paired-end reads

761 (FASTQ files) were merged with FastqJoin and quality filtered with a Q-score cutoff of 20.

762 Merged sequencing reads were denoised using using DADA2 (Ref). Taxonomic classification

763 was generated using a pre-trained naive Bayes classifier on the basis of the bacterial 16S rRNA

764 Greengenes reference database and QIIME2 (https://qiime2.org).

765

\section{CONTACT FOR REAGENT AND RESOURCE SHARING}

767 Further information and requests for resources and reagents should be directed to and will be

768 fulfilled by the Lead Contact, Matthew K Waldor (mwaldor@ research.bwh.harvard.edu)

770 Supplementary items

771 Table S1: Diarrheal fluid proteomes

772 Table S2: Pathway enrichment

773 Table S3: SPLASHM proteome

774 Table S4: Glycomic data 


\section{References}

1. Stow JL, Condon ND. The cell surface environment for pathogen recognition and entry. Clin Transl Immunol [Internet]. 2016 Apr 15 [cited 2020 Dec 20];5(4):e71. Available from: http://doi.wiley.com/10.1038/cti.2016.15

2. Hornef MW, Wick MJ, Rhen M, Normark S. Bacterial strategies for overcoming host innate and adaptive immune responses [Internet]. Vol. 3, Nature Immunology. Nat Immunol; 2002 [cited 2020 Dec 20]. p. 1033-40. Available from: https://pubmed.ncbi.nlm.nih.gov/12407412/

3. Costa TRD, Felisberto-Rodrigues C, Meir A, Prevost MS, Redzej A, Trokter M, et al. Secretion systems in Gram-negative bacteria: Structural and mechanistic insights [Internet]. Vol. 13, Nature Reviews Microbiology. Nature Publishing Group; 2015 [cited 2020 Dec 20]. p. 343-59. Available from: https://pubmed.ncbi.nlm.nih.gov/25978706/

4. Ting L, Rad R, Gygi SP, Haas W. MS3 eliminates ratio distortion in isobaric multiplexed quantitative proteomics. Nat Methods [Internet]. 2011 Nov [cited 2020 Dec 20];8(11):937-40. Available from: https://pubmed.ncbi.nlm.nih.gov/21963607/

5. Weekes MP, Tomasec P, Huttlin EL, Fielding CA, Nusinow D, Stanton RJ, et al. Quantitative temporal viromics: An approach to investigate host-pathogen interaction. Cell [Internet]. 2014 Jun 5 [cited 2020 Dec 24];157(6):1460-72. Available from: https://pubmed.ncbi.nlm.nih.gov/24906157/

6. Toledo AG, Golden G, Campos AR, Cuello H, Sorrentino J, Lewis N, et al. Proteomic atlas of organ vasculopathies triggered by Staphylococcus aureus sepsis. Nat Commun [Internet]. 2019 Dec 1 [cited 2020 Dec 23];10(1). Available from: https://pubmed.ncbi.nlm.nih.gov/31604940/

7. Zhang Y, Song G, Lal NK, Nagalakshmi U, Li Y, Zheng W, et al. TurboID-based proximity labeling reveals that UBR7 is a regulator of N NLR immune receptor-mediated immunity. Nat Commun [Internet]. 2019 Dec 1 [cited 2021 Jan 1];10(1). Available from:

https://pubmed.ncbi.nlm.nih.gov/31324801/

8. D'Costa VM, Coyaud E, Boddy KC, Laurent EMN, St-Germain J, Li T, et al. BioID screen of Salmonella type 3 secreted effectors reveals host factors involved in vacuole positioning and stability during infection. Nat Microbiol [Internet]. 2019 Dec 1 [cited 2021 Jan 1];4(12):2511-22. Available from: https://pubmed.ncbi.nlm.nih.gov/31611645/

9. Olson MG, Widner RE, Jorgenson LM, Lawrence A, Lagundzin D, Woods NT, et al. Proximity labeling to map host-pathogen interactions at the membrane of a bacterium-containing vacuole in chlamydia trachomatis-infected human cells. Infect Immun [Internet]. 2019 Nov 1 [cited 2021 Jan 1];87(11). Available from: https://doi.org/10

10. Clemens JD, Nair GB, Ahmed T, Qadri F, Holmgren J. Cholera [Internet]. Vol. 390, The Lancet. Lancet Publishing Group; 2017 [cited 2020 Dec 20]. p. 1539-49. Available from:

https://pubmed.ncbi.nlm.nih.gov/28302312/

11. Balakrishnan VS. Cholera in Yemen. Lancet Infect Dis [Internet]. 2017 Jul 1 [cited 2020 Dec 20];17(7):700-1. Available from: https://pubmed.ncbi.nlm.nih.gov/28737493/

12. Ali M, Nelson AR, Lopez AL, Sack DA. Updated global burden of cholera in endemic countries. PLoS Negl Trop Dis [Internet]. 2015 Jun 4 [cited 2021 Jan 1];9(6). Available from: https://pubmed.ncbi.nlm.nih.gov/26043000/

13. Dizon JJ, Fukumi H, Barua D, Valera J, Jayme F, Gomez F, et al. Studies on cholera carriers. Bull World Health Organ [Internet]. 1967 [cited 2021 Jan 1];37(5):737-43. Available from: https://pubmed.ncbi.nlm.nih.gov/5300876/

14. Hardy SJS, Holmgren J, Johansson S, Sanchez J, Hirst TR. Coordinated assembly of multisubunit proteins: Oligomerization of bacterial enterotoxins in vivo and in vitro. Proc Natl Acad Sci U S A [Internet]. 1988 [cited 2021 Jan 1];85(19):7109-13. Available from:

https://pubmed.ncbi.nlm.nih.gov/3050987/

15. Wernick NLB, Chinnapen DJF, Cho JA, Lencer WI. Cholera toxin: An intracellular journey into the cytosol by way of the endoplasmic reticulum [Internet]. Vol. 2, Toxins. Toxins (Basel); 2010 
[cited 2021 Jan 1]. p. 310-25. Available from: https://pubmed.ncbi.nlm.nih.gov/22069586/

16. De SN. Enterotoxicity of bacteria-free culture-filtrate of vibrio cholerae. Nature [Internet]. 1959

[cited 2021 Jan 5];183(4674):1533-4. Available from: https://pubmed.ncbi.nlm.nih.gov/13666809/

17. Gabriel SE, Brigman KN, Koller BH, Boucher RC, Stutts MJ. Cystic fibrosis heterozygote resistance to cholera toxin in the cystic fibrosis mouse model. Science (80- ) [Internet]. 1994 [cited 2021 Jan 1];266(5182):107-9. Available from: https://pubmed.ncbi.nlm.nih.gov/7524148/

18. Levine MM, Kaper JB, Black RE, Clements ML. New knowledge on pathogenesis of bacterial enteric infections as applied to vaccine development [Internet]. Vol. 47, Microbiological Reviews. Microbiol Rev; 1983 [cited 2021 Jan 1]. p. 510-50. Available from:

https://pubmed.ncbi.nlm.nih.gov/6363898/

19. Herrington DA, Hall RH, Losonsky G, Mekalanos JJ, Taylor RK, Levine MM. Toxin, toxincoregulated pili, and the toxR regulon are essential for Vibrio Cholerae pathogenesis in humans. J Exp Med [Internet]. 1988 Oct 1 [cited 2020 Dec 20];168(4):1487-92. Available from:

https://pubmed.ncbi.nlm.nih.gov/2902187/

20. Silva AJ, Leitch GJ, Camilli A, Benitez JA. Contribution of hemagglutinin/protease and motility to the pathogenesis of El Tor biotype cholera. Infect Immun [Internet]. 2006 Apr [cited 2021 Jan 1];74(4):2072-9. Available from: https://pubmed.ncbi.nlm.nih.gov/16552036/

21. Butler SM, Camilli A. Going against the grain: Chemotaxis and infection in Vibrio cholerae [Internet]. Vol. 3, Nature Reviews Microbiology. Nat Rev Microbiol; 2005 [cited 2021 Jan 1]. p. 611-20. Available from: https://pubmed.ncbi.nlm.nih.gov/16012515/

22. Rothenbacher FP, Zhu J. Efficient responses to host and bacterial signals during Vibrio cholerae colonization [Internet]. Vol. 5, Gut Microbes. Gut Microbes; 2013 [cited 2021 Jan 1]. Available from: https://pubmed.ncbi.nlm.nih.gov/24256715/

23. Richardson SH. Animal Models in Cholera Research. In: Vibrio cholerae and Cholera [Internet]. ASM Press; 2014 [cited 2021 Jan 5]. p. 203-26. Available from: https://www.asmscience.org/content/book/10.1128/9781555818364.chap14

24. Ritchie JM, Rui H, Bronson RT, Waldor MK. Back to the future: Studying cholera pathogenesis using infant Rabbits. MBio [Internet]. 2010 [cited 2020 Dec 20];1(1). Available from: /pmc/articles/PMC2912669/?report=abstract

25. Mandlik A, Livny J, Robins WP, Ritchie JM, Mekalanos JJ, Waldor MK. RNA-seq-based monitoring of infection-linked changes in vibrio cholerae gene expression. Cell Host Microbe [Internet]. 2011 Aug 18 [cited 2021 Jan 1];10(2):165-74. Available from:

/pmc/articles/PMC3166260/?report=abstract

26. Fu Y, Waldor MK, Mekalanos JJ. Tn-seq analysis of vibrio cholerae intestinal colonization reveals a role for T6SS-mediated antibacterial activity in the host. Cell Host Microbe [Internet]. 2013 Dec 11 [cited 2021 Jan 1];14(6):652-63. Available from: https://pubmed.ncbi.nlm.nih.gov/24331463/

27. Pritchard JR, Chao MC, Abel S, Davis BM, Baranowski C, Zhang YJ, et al. ARTIST: HighResolution Genome-Wide Assessment of Fitness Using Transposon-Insertion Sequencing. Viollier PH, editor. PLoS Genet [Internet]. 2014 Nov 6 [cited 2021 Jan 1];10(11):e1004782. Available from: https://dx.plos.org/10.1371/journal.pgen.1004782

28. Hubbard TP, Billings G, Dörr T, Sit B, Warr AR, Kuehl CJ, et al. A live vaccine rapidly protects against cholera in an infant rabbit model. Sci Transl Med [Internet]. 2018 Jun 13 [cited 2021 Jan 1];10(445). Available from: http://stm.sciencemag.org/

29. Kamp HD, Patimalla-Dipali B, Lazinski DW, Wallace-Gadsden F, Camilli A. Gene Fitness Landscapes of Vibrio cholerae at Important Stages of Its Life Cycle. Klose KE, editor. PLoS Pathog [Internet]. 2013 Dec 26 [cited 2021 Jan 5];9(12):e1003800. Available from: https://dx.plos.org/10.1371/journal.ppat.1003800

30. LaRocque RC, Krastins B, Harris JB, Lebrun LM, Parker KC, Chase M, et al. Proteomic analysis of Vibrio cholerae in human stool. Infect Immun [Internet]. 2008 Sep [cited 2020 Dec 27];76(9):4145-51. Available from: https://pubmed.ncbi.nlm.nih.gov/18591230/

31. Altindis E, Fu Y, Mekalanos JJ. Proteomic analysis of Vibrio cholerae outer membrane vesicles. 
Proc Natl Acad Sci U S A [Internet]. 2014 Apr 15 [cited 2021 Jan 1];111(15). Available from: https://pubmed.ncbi.nlm.nih.gov/24706774/

32. Hatzios SK, Abel S, Martell J, Hubbard T, Sasabe J, Munera D, et al. Chemoproteomic profiling of host and pathogen enzymes active in cholera. Nat Chem Biol [Internet]. 2016 Apr 1 [cited 2020 Dec 20];12(4):268-74. Available from: https://pubmed.ncbi.nlm.nih.gov/26900865/

33. Howell M, Dumitrescu DG, Blankenship LR, Herkert D, Hatzios SK. Functional characterization of a subtilisin-like serine protease from Vibrio cholerae. J Biol Chem [Internet]. 2019 Jun 21 [cited 2021 Jan 1];294(25):9888-900. Available from: https://pubmed.ncbi.nlm.nih.gov/31076508/

34. Chin C-S, Sorenson J, Harris JB, Robins WP, Charles RC, Jean-Charles RR, et al. The Origin of the Haitian Cholera Outbreak Strain. N Engl J Med [Internet]. 2011 Jan 6 [cited 2021 Jan 1];364(1):33-42. Available from: https://pubmed.ncbi.nlm.nih.gov/21142692/

35. Rivera-Chávez F, Mekalanos JJ. Cholera toxin promotes pathogen acquisition of host-derived nutrients. Nature [Internet]. 2019 Aug 8 [cited 2021 Jan 1];572(7768):244-8. Available from: https://pubmed.ncbi.nlm.nih.gov/31367037/

36. Olivier V, Queen J, Satchell KJF. Successful Small Intestine Colonization of Adult Mice by Vibrio cholerae Requires Ketamine Anesthesia and Accessory Toxins. Valdivia RH, editor. PLoS One [Internet]. 2009 Oct 8 [cited 2021 Jan 1];4(10):e7352. Available from:

https://dx.plos.org/10.1371/journal.pone.0007352

37. Lindblad-Toh K, Garber M, Zuk O, Lin MF, Parker BJ, Washietl S, et al. A high-resolution map of human evolutionary constraint using 29 mammals. Nature [Internet]. 2011 Oct 27 [cited 2021 Jan 1];478(7370):476-82. Available from: https://pubmed.ncbi.nlm.nih.gov/21993624/

38. Vuk-Pavlovic Z, Standing JE, Crouch EC, Limper AH. Carbohydrate recognition domain of surfactant protein D mediates interactions with Pneumocystis carinii glycoprotein A. Am J Respir Cell Mol Biol [Internet]. 2001 [cited 2020 Dec 27];24(4):475-84. Available from: https://pubmed.ncbi.nlm.nih.gov/11306442/

39. Sarashina-Kida H, Negishi H, Nishio J, Suda W, Nakajima Y, Yasui-Kato M, et al. Gallbladderderived surfactant protein $\mathrm{D}$ regulates gut commensal bacteria for maintaining intestinal homeostasis. Proc Natl Acad Sci U S A [Internet]. 2017 Sep 19 [cited 2020 Dec 20];114(38):10178-83. Available from: https://www.pnas.org/content/114/38/10178

40. Crouch EC, Smith K, McDonald B, Briner D, Linders B, McDonald J, et al. Species differences in the carbohydrate binding preferences of surfactant protein D. Am J Respir Cell Mol Biol [Internet]. $2006 \mathrm{Jul}$ [cited 2020 Dec 27];35(1):84-94. Available from: https://pubmed.ncbi.nlm.nih.gov/16514117/

41. Tajima Y, Tsuruta M, Hasegawa H, Okabayashi K, Ishida T, Yahagi M, et al. Association of surfactant protein D with pulmonary metastases from colon cancer. Oncol Lett [Internet]. 2020 Oct 5 [cited 2020 Dec 20];20(6). Available from: https://pubmed.ncbi.nlm.nih.gov/33123238/

42. Jounblat R, Kadioglu A, Iannelli F, Pozzi G, Eggleton P, Andrew PW. Binding and Agglutination of Streptococcus pneumoniae by Human Surfactant Protein D (SP-D) Vary between Strains, but SP-D Fails to Enhance Killing by Neutrophils. Infect Immun [Internet]. 2004 Feb [cited 2020 Dec 20];72(2):709-16. Available from: https://pubmed.ncbi.nlm.nih.gov/14742512/

43. Reinhardt A, Wehle M, Geissner A, Crouch EC, Kang Y, Yang Y, et al. Structure binding relationship of human surfactant protein D and various lipopolysaccharide inner core structures. $\mathrm{J}$ Struct Biol [Internet]. 2016 Sep 1 [cited 2020 Dec 27];195(3):387-95. Available from: https://pubmed.ncbi.nlm.nih.gov/27350640/

44. Hartshorn KL, Crouch EC, White MR, Eggleton P, Tauber AI, Chang D, et al. Evidence for a protective role of pulmonary surfactant protein D (SP-D) against influenza A viruses. J Clin Invest. 1994 Jul 1;94(1):311-9.

45. Ng WC, Tate MD, Brooks AG, Reading PC. Soluble host defense lectins in innate immunity to influenza virus [Internet]. Vol. 2012, Journal of Biomedicine and Biotechnology. Hindawi Limited; 2012 [cited 2021 Jan 1]. p. 14. Available from: /pmc/articles/PMC3362216/?report=abstract 
46. Weekes MP, Antrobus R, Talbot S, Hör S, Simecek N, Smith DL, et al. Proteomic plasma membrane profiling reveals an essential role for gp96 in the cell surface expression of LDLR family members, including the LDL receptor and LRP6. In: Journal of Proteome Research [Internet]. J Proteome Res; 2012 [cited 2020 Dec 24]. p. 1475-84. Available from: https://pubmed.ncbi.nlm.nih.gov/22292497/

47. Nilsson Bark SK, Ahmad R, Dantzler K, Lukens AK, De Niz M, Szucs MJ, et al. Quantitative proteomic profiling reveals novel plasmodium falciparum surface antigens and possible vaccine candidates. Mol Cell Proteomics [Internet]. 2018 Jan 1 [cited 2021 Jan 1];17(1):43-60. Available from: /pmc/articles/PMC5750850/?report=abstract

48. Ryback JN, Ettorre A, Kaissling B, Giavazzi R, Neri D, Elia G. In vivo protein biotinylation for identification of organ-specific antigens accessible from the vasculature. Nat Methods [Internet]. 2005 Apr [cited 2021 Jan 1];2(4):291-8. Available from:

https://pubmed.ncbi.nlm.nih.gov/15782212/

49. Pressler K, Mitterer F, Vorkapic D, Reidl J, Oberer M, Schild S. Characterization of Vibrio cholerae's Extracellular Nuclease Xds. Front Microbiol [Internet]. 2019 Sep 10 [cited 2020 Dec 27];10. Available from: /pmc/articles/PMC6746945/?report=abstract

50. Edwin A, Persson C, Mayzel M, Wai SN, Öhman A, Karlsson BG, et al. Structure of the Nterminal domain of the metalloprotease PrtV from Vibrio cholerae. Protein Sci [Internet]. 2015 Dec 1 [cited 2021 Jan 1];24(12):2076-80. Available from:

https://pubmed.ncbi.nlm.nih.gov/26434928/

51. Mey AR, Payne SM. Haem utilization in Vibrio cholerae involves multiple tonB-dependent haem receptors. Mol Microbiol [Internet]. 2001 [cited 2021 Jan 1];42(3):835-49. Available from: https://pubmed.ncbi.nlm.nih.gov/11722746/

52. Hughes KJ, Everiss KD, Kovach ME, Peterson KM. Isolation and characterization of the Vibrio cholerae acfA gene, required for efficient intestinal colonization. Gene [Internet]. 1995 Apr 14 [cited 2021 Jan 1];156(1):59-61. Available from: https://pubmed.ncbi.nlm.nih.gov/7737517/

53. Gavins FNE, Hickey MJ. Annexin A1 and the regulation of innate and adaptive immunity. Front Immunol [Internet]. 2012 Nov 27 [cited 2021 Jan 1];3(NOV):354. Available from:

www.frontiersin.org

54. Sheikh MH, Solito E. Annexin A1: Uncovering the many talents of an old protein [Internet]. Vol. 19, International Journal of Molecular Sciences. MDPI AG; 2018 [cited 2020 Dec 20]. Available from: https://pubmed.ncbi.nlm.nih.gov/29614751/

55. Sarr D, Tóth E, Gingerich A, Rada B. Antimicrobial actions of dual oxidases and lactoperoxidase [Internet]. Vol. 56, Journal of Microbiology. Microbiological Society of Korea; 2018 [cited 2020 Dec 20]. p. 373-86. Available from: /pmc/articles/PMC7336354/?report=abstract

56. Al-Shehri SS, Duley JA, Bansal N. Xanthine oxidase-lactoperoxidase system and innate immunity: Biochemical actions and physiological roles. Vol. 34, Redox Biology. Elsevier B.V.; 2020. p. 101524.

57. Arur S, Uche UE, Rezaul K, Fong M, Scranton V, Cowan AE, et al. Annexin I is an endogenous ligand that mediates apoptotic cell engulfment. Dev Cell [Internet]. 2003 Apr 1 [cited 2021 Jan 1];4(4):587-98. Available from: https://pubmed.ncbi.nlm.nih.gov/12689596/

58. Romauch M. Zinc- $\alpha 2$-glycoprotein is an inhibitor of amine oxidase copper-containing 3 [Internet]. bioRxiv. bioRxiv; 2019 [cited 2021 Jan 1]. p. 727214 . Available from: https://doi.org/10.1101/727214

59. Hassan MI, Bilgrami S, Kumar V, Singh N, Yadav S, Kaur P, et al. Crystal Structure of the Novel Complex Formed between Zinc $\alpha 2-$ Glycoprotein (ZAG) and Prolactin-Inducible Protein (PIP) from Human Seminal Plasma. J Mol Biol [Internet]. 2008 Dec [cited 2021 Jan 1];384(3):663-72. Available from: https://pubmed.ncbi.nlm.nih.gov/18930737/

60. Sánchez LM. Crystal structure of human ZAG, a fat-depleting factor related to MHC molecules. Science (80- ) [Internet]. 1999 Mar 19 [cited 2021 Jan 1];283(5409):1914-9. Available from: https://pubmed.ncbi.nlm.nih.gov/10206894/ 
61. Halenius A, Gerke C, Hengel H. Classical and non-classical MHC I molecule manipulation by human cytomegalovirus: so many targets-but how many arrows in the quiver? Cell Mol Immunol [Internet]. 2014 [cited 2021 Jan 5];12:139-53. Available from: www.nature.com/cmi

62. Stowell SR, Arthur CM, Mcbride R, Berger O, Razi N, Heimburg-Molinaro J, et al. Microbial glycan microarrays define key features of host-microbial interactions. Nat Chem Biol [Internet]. 2014 [cited 2020 Dec 21];10(6):470-6. Available from:

https://pubmed.ncbi.nlm.nih.gov/24814672/

63. Palm NW, De Zoete MR, Cullen TW, Barry NA, Stefanowski J, Hao L, et al. Immunoglobulin A coating identifies colitogenic bacteria in inflammatory bowel disease. Cell [Internet]. 2014 Aug 28 [cited 2020 Dec 20];158(5):1000-10. Available from:

/pmc/articles/PMC4174347/?report=abstract

64. Metchnikoff E. Recherches sur le cholera et les vibrions . Ann Inst Pasteur [Internet]. 1894 [cited 2021 Jan 1];8-557. Available from:

https://scholar.google.com/scholar_lookup?author=E.+Metchnikoff\&title=Recherches+sur+le+cho lera+et+les+vibrions.+Receptivite+des+jeunes+lapins+pour+le+cholera+intestinal\&publication_y ear $=1894 \&$ journal=Ann. + Inst. + Pasteur+\%28Paris\%29\&volume $=8$

65. Sit B, Zhang T, Fakoya B, Akter A, Biswas R, Ryan ET, et al. Oral immunization with a probiotic cholera vaccine induces broad protective immunity against vibrio cholerae colonization and disease in mice. PLoS Negl Trop Dis [Internet]. 2019 May 1 [cited 2021 Jan 1];13(5). Available from: /pmc/articles/PMC6561597/?report=abstract

66. Nelson EJ, Chowdhury A, Harris JB, Begum YA, Chowdhury F, Khan AI, et al. Complexity of rice-water stool from patients with Vibrio cholerae plays a role in the transmission of infectious diarrhea. Proc Natl Acad Sci U S A. 2007;104(48):19091-6.

67. Forstner JF, Roomi NW, Fahim REF, Forstner GG. Cholera toxin stimulates secretion of immunoreactive intestinal mucin. Am J Physiol - Gastrointest Liver Physiol [Internet]. 1981 [cited 2020 Dec 20];3(1). Available from: https://pubmed.ncbi.nlm.nih.gov/7457607/

68. Crouch EC. Surfactant protein-D and pulmonary host defense [Internet]. Vol. 1, Respiratory Research. BioMed Central; 2000 [cited 2021 Jan 1]. p. 93-108. Available from: http://respiratoryresearch.biomedcentral.com/articles/10.1186/rr19

69. Madan T, Kishore U. Surfactant Protein D Recognizes Multiple Fungal Ligands: A Key Step to Initiate and Intensify the Anti-fungal Host Defense [Internet]. Vol. 10, Frontiers in Cellular and Infection Microbiology. Frontiers Media S.A.; 2020 [cited 2021 Jan 1]. Available from: https://pubmed.ncbi.nlm.nih.gov/32547959/

70. Sasabe J, Miyoshi Y, Rakoff-Nahoum S, Zhang T, Mita M, Davis BM, et al. Interplay between microbial d-amino acids and host d-amino acid oxidase modifies murine mucosal defence and gut microbiota. Nat Microbiol [Internet]. 2016 Jul 25 [cited 2020 Dec 20];1(10):16125. Available from: https://www.ncbi.nlm.nih.gov/pmc/articles/PMC5074547/

71. Hang L, John M, Asaduzzaman M, Bridges EA, Vanderspurt C, Kirn TJ, et al. Use of in vivoinduced antigen technology (IVIAT) to identify genes uniquely expressed during human infection with Vibrio cholerae. Proc Natl Acad Sci U S A [Internet]. 2003 Jul 8 [cited 2021 Jan 1];100(14):8508-13. Available from: https://pubmed.ncbi.nlm.nih.gov/12826608/

72. Wesener DA, Wangkanont K, McBride R, Song X, Kraft MB, Hodges HL, et al. Recognition of microbial glycans by human intelectin-1. Nat Struct Mol Biol [Internet]. 2015 Aug 7 [cited 2020 Dec 21];22(8):603-10. Available from: https://pubmed.ncbi.nlm.nih.gov/26148048/

73. Santin YG, Camy CE, Zoued A, Doan T, Aschtgen MS, Cascales E. Role and recruitment of the TAGL peptidoglycan-binding protein during type VI secretion system biogenesis. J Bacteriol. 2019;201(12).

74. Fleurie A, Zoued A, Alvarez L, Hines KM, Cava F, Xu L, et al. A vibrio cholerae BoLA-like protein is required for proper cell shape and cell envelope integrity. MBio. $2019 \mathrm{Jul} 1 ; 10(4)$.

75. Kuehl CJ, D'gama JD, Warr AR, Waldor MK. An oral inoculation infant rabbit model for shigella infection. MBio [Internet]. 2020 Jan 1 [cited 2020 Dec 24];11(1). Available from: 
https://pubmed.ncbi.nlm.nih.gov/31964739/

76. Warr AR, Kuehl CJ, Waldor MK. Shiga toxin remodels the intestinal epithelial transcriptional response to Enterohemorrhagic Escherichia coli. bioRxiv [Internet]. 2020 Aug 11 [cited 2021 Jan 1];2020.08.11.245555. Available from:

https://www.biorxiv.org/content/10.1101/2020.08.11.245555v1

77. Korotkevich G, Sukhov V, Sergushichev A. Fast gene set enrichment analysis. bioRxiv [Internet]. 2016 Oct 22 [cited 2021 Jan 1];060012. Available from: https://doi.org/10.1101/060012 


\section{Figure 1}

A

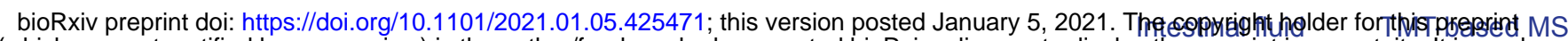
(which was not certified by peer review) is the author/funder, who has granted bioRxiv a license to display the preprint in perpetuity. It is made

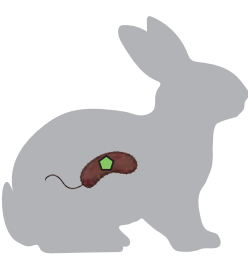

V. cholerae

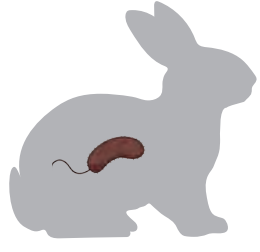

V. cholerae $\Delta c t x$ available under aCC-BY-NC-ND 4.0 International license.

B

V. cholerae $\Delta c t x 2$

V. cholerae $\Delta$ ctx 1

Mock 3

Mock 1

Mock 2

V. cholerae 2

V. cholerae 1

CT 3

CT 1

CT 2
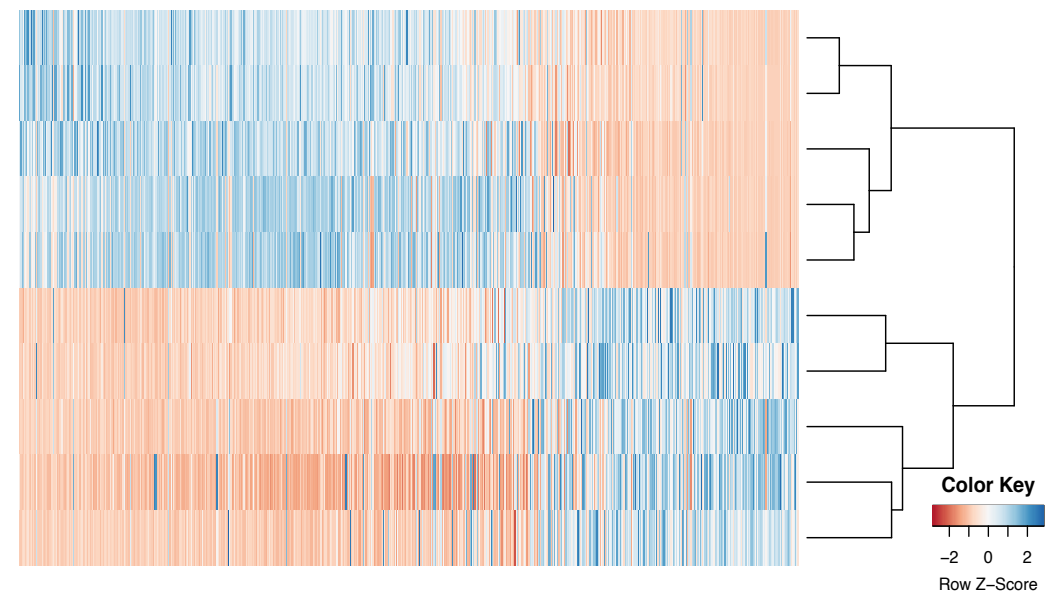

C

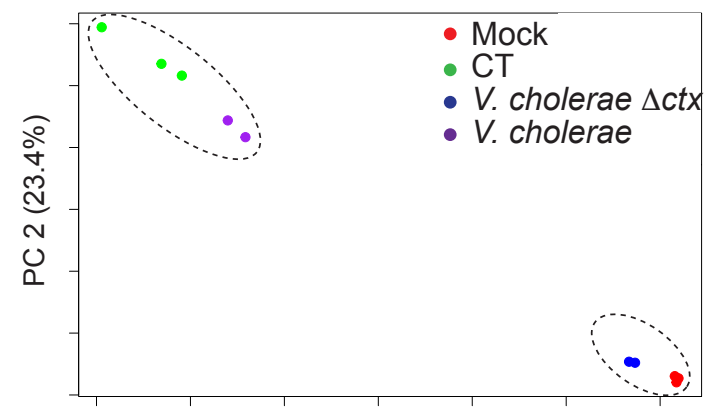

PC 1 (63.7\%)
D

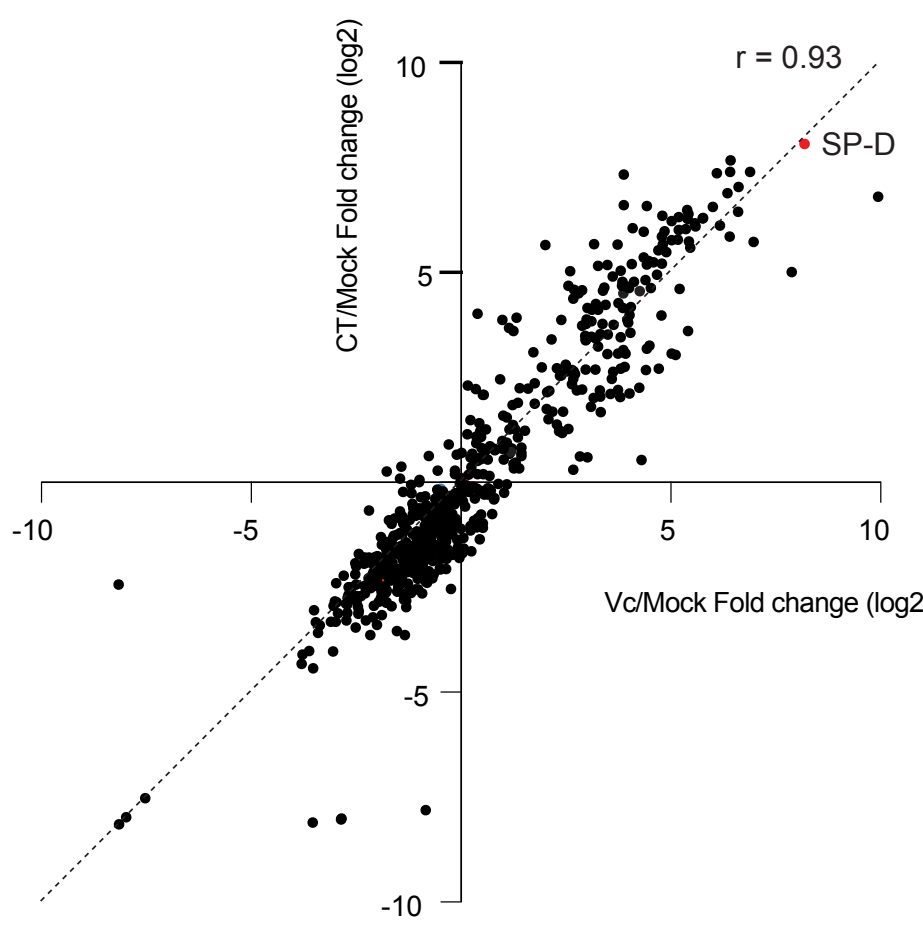

E

NES

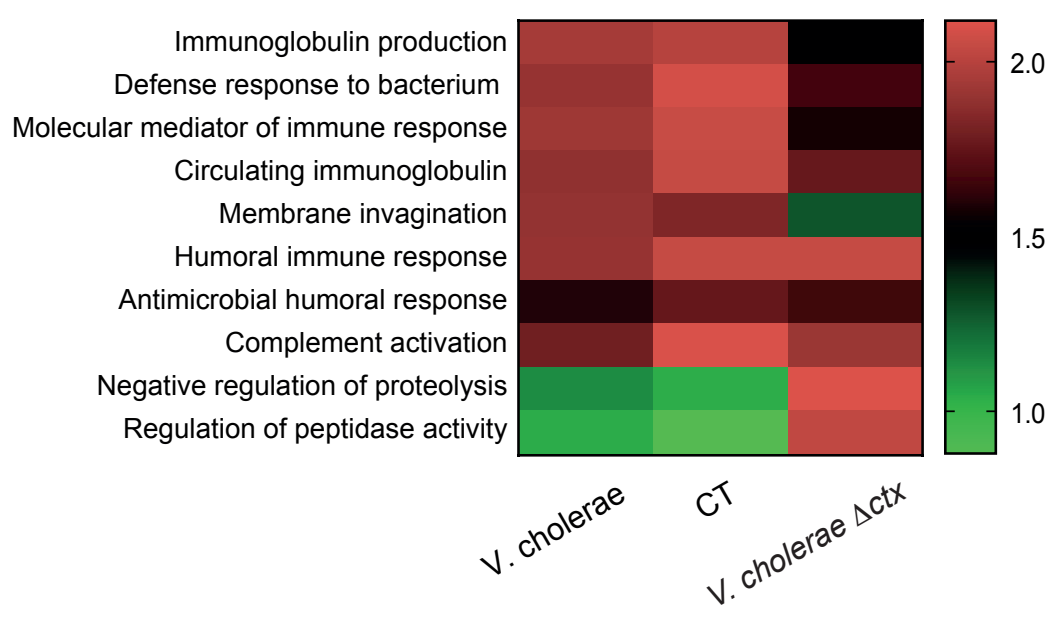




\section{Figure 2}

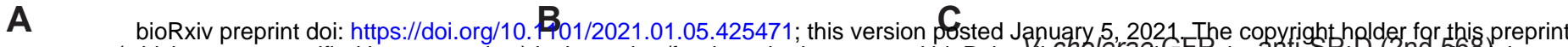

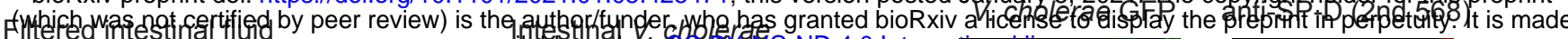

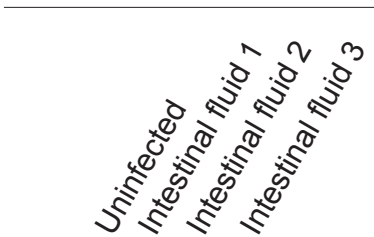

$198-$

$62-$

$49-$

38 - 미-SP-D

$28-$

$18-$

$14-$

D

Cultured V. cholerae

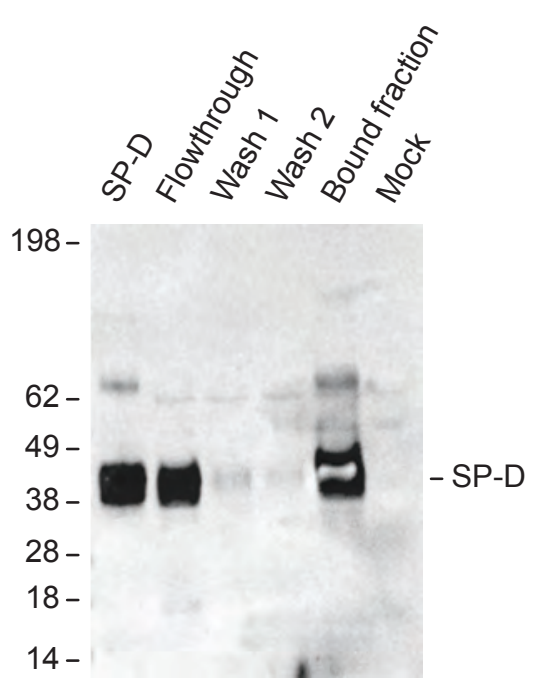

E

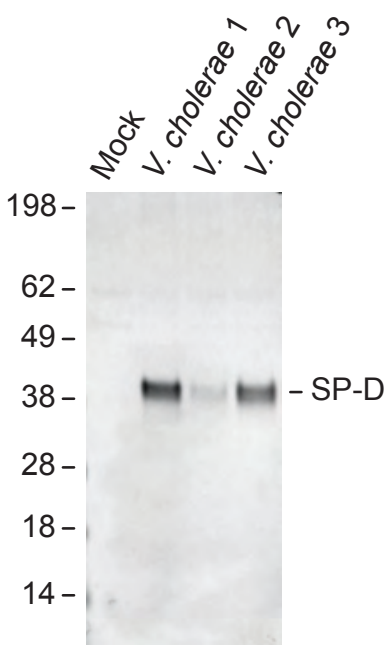

\section{F}
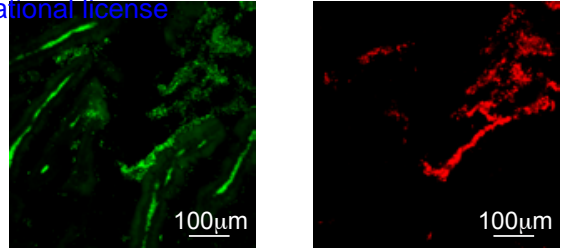

DAPI

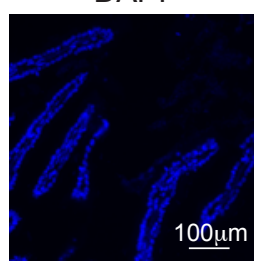

phalloidin

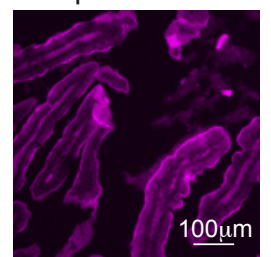

Merge

Zoom
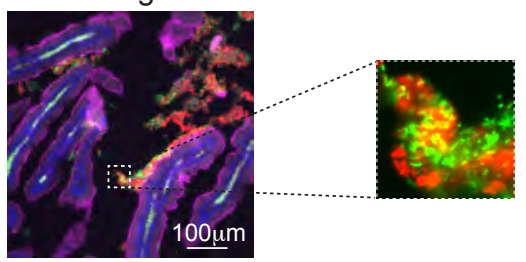

SP-D

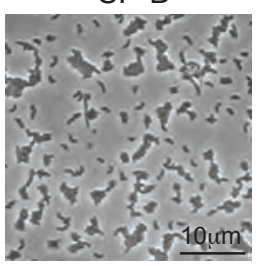

+ SP-D $(10 \mu \mathrm{g} / \mathrm{ml})$

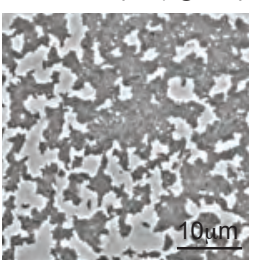

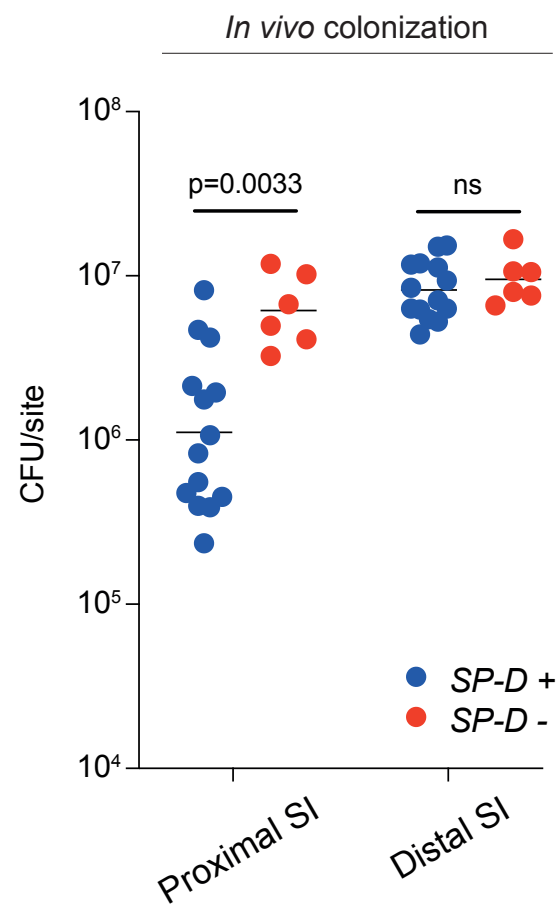




\section{Figure 3}
A
Bacterial isolation
Surface-exposed proteome labeling

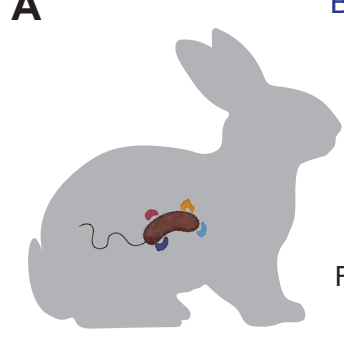

\section{B}

Host-derived proteins

Bacterial proteins

Surface-exposed proteome 1

\section{Surface-exposed} proteome 2

\section{Surface-exposed} proteome 3

Intestinal proteome 1

Intestinal proteome 2

Intestinal proteome 3
C

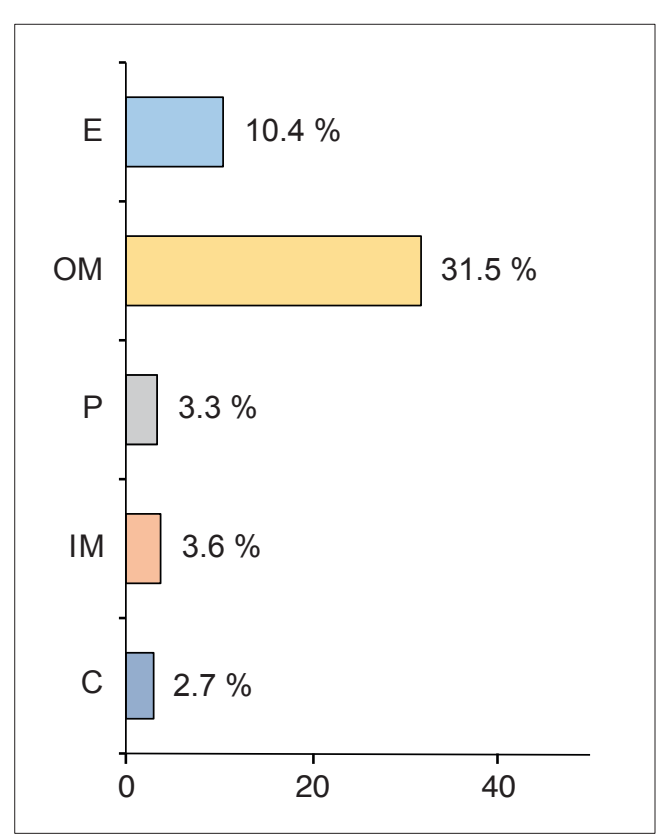

Precursor ion

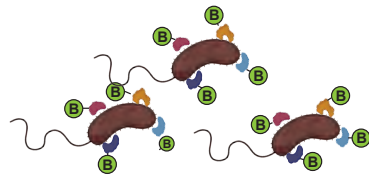

Streptavidin magnetic beads

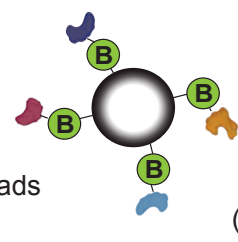

(Tandem Mass Tags)

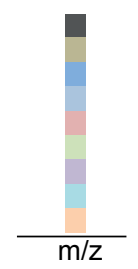

Reporter ion quantification

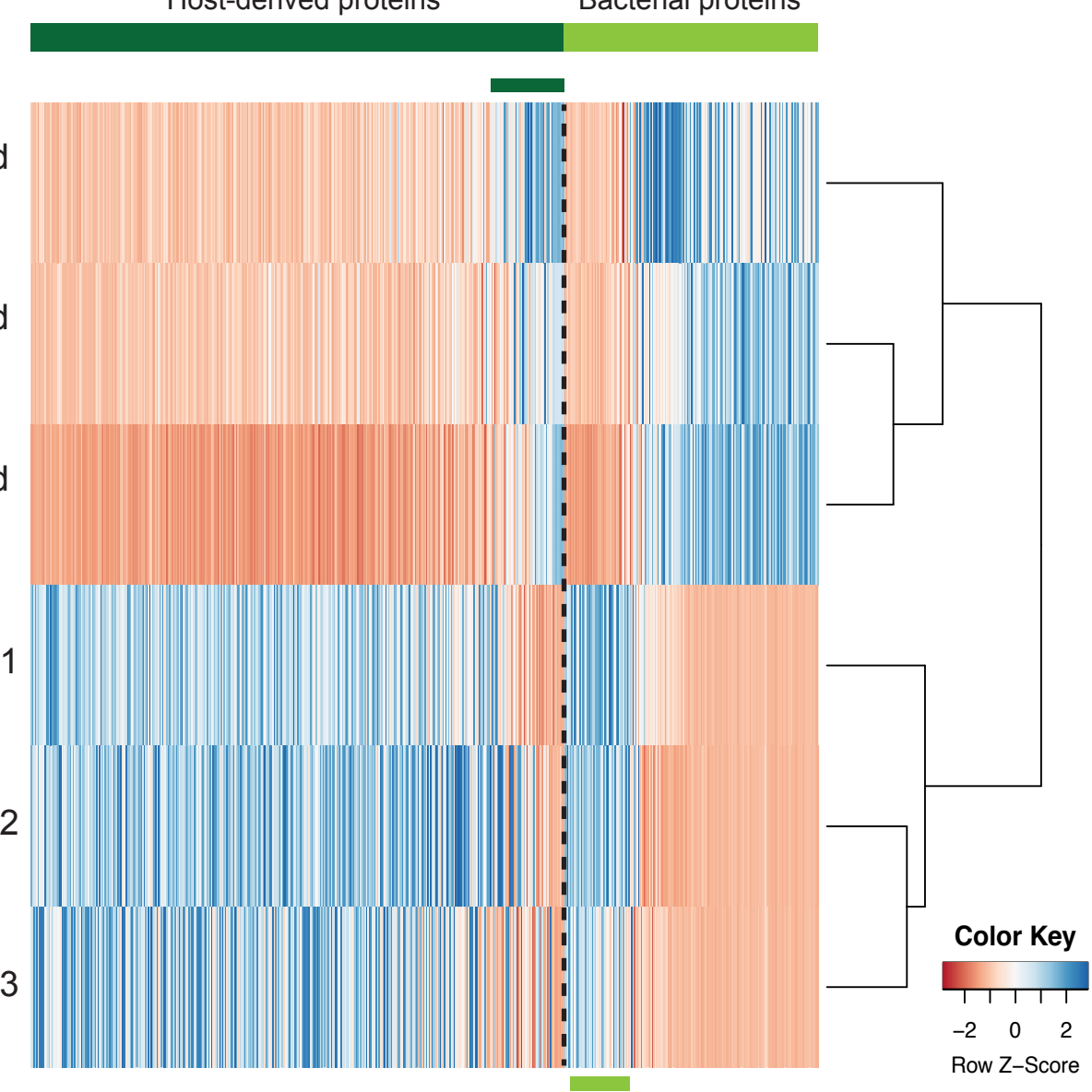

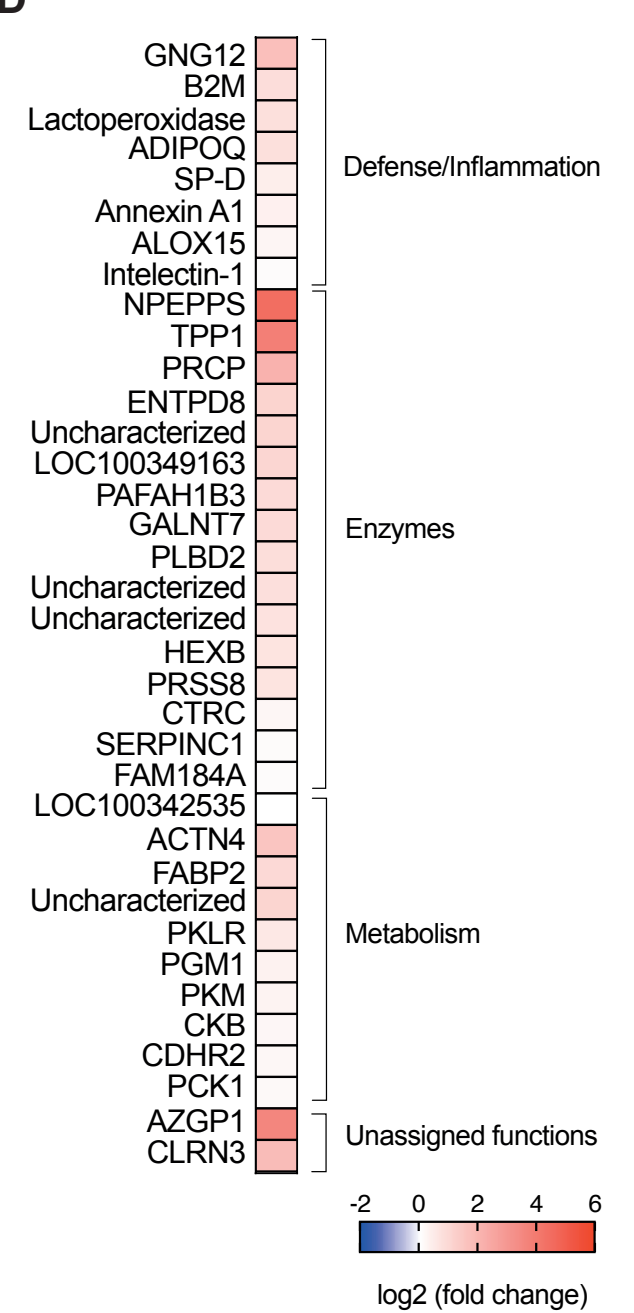




\section{Figure 4}

Intestinal fluid $V$. cholerae

A bioRxiv preprint doi: https://doi.org/1 0.1101/2021.01.05.425471; this version posted January 5, 2021. The copyright holder for this preprint A (which was not certified by peer revi is the author/funder, who has granted bioR a license to display the preprint in perpetuity. It is made
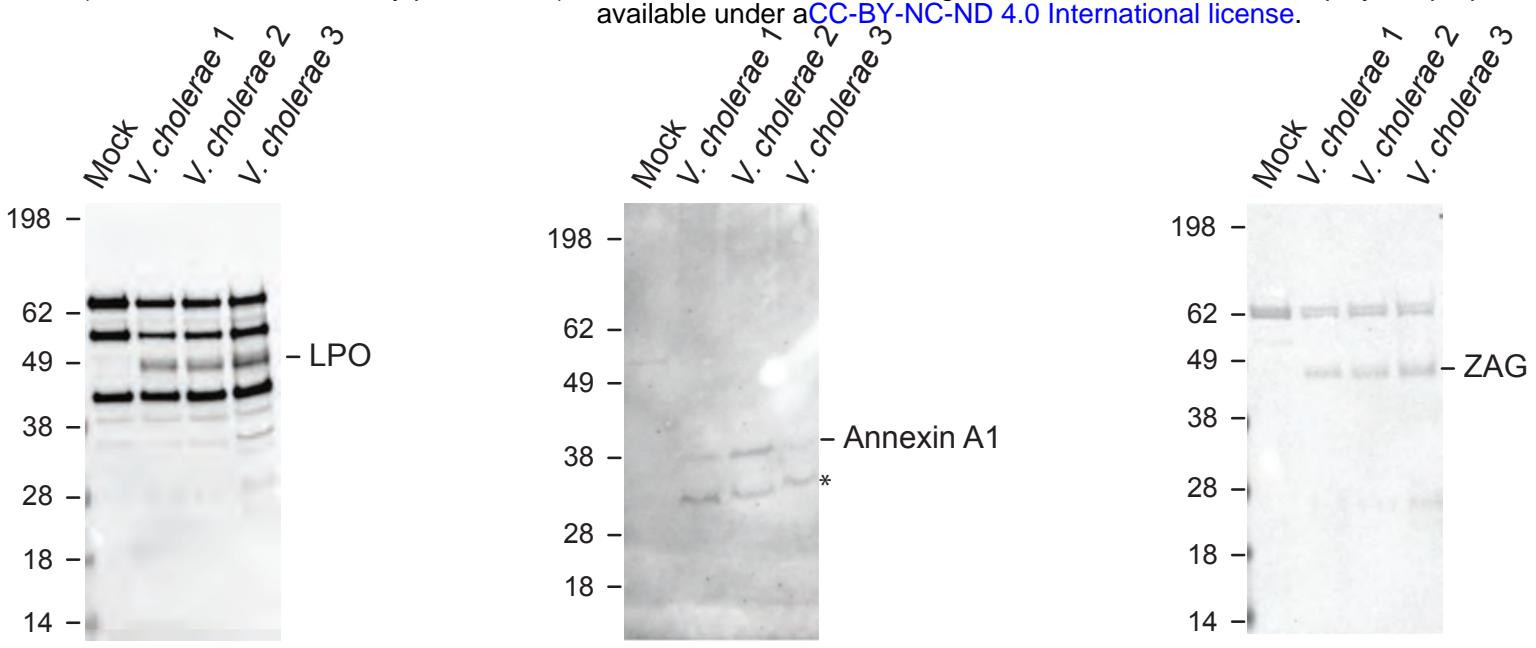

\section{Cultured V. cholerae}

D

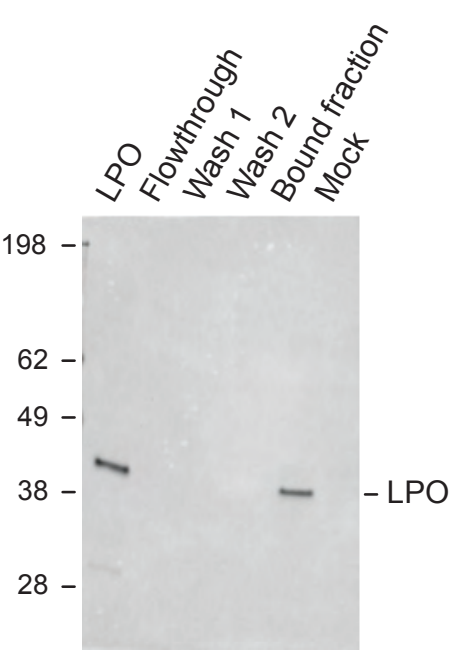

E

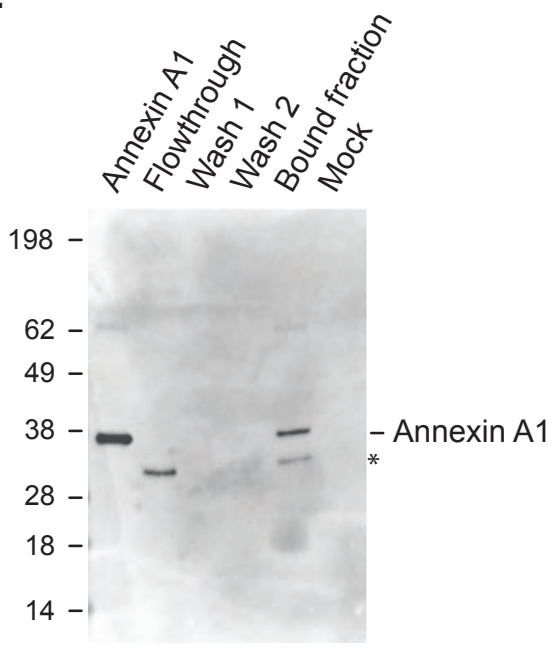

$\mathbf{F}$

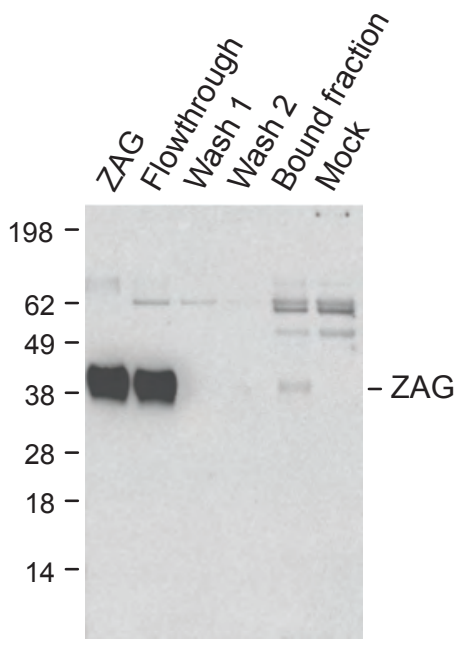

G

ZAG

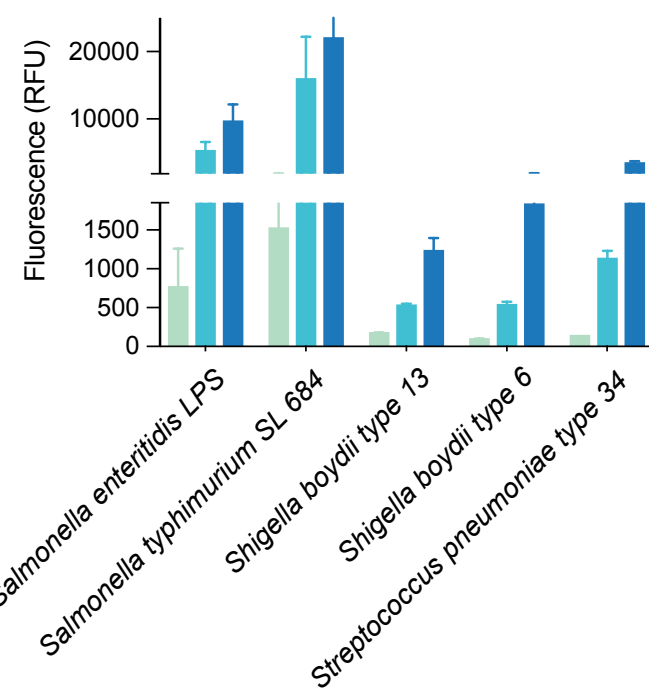

H

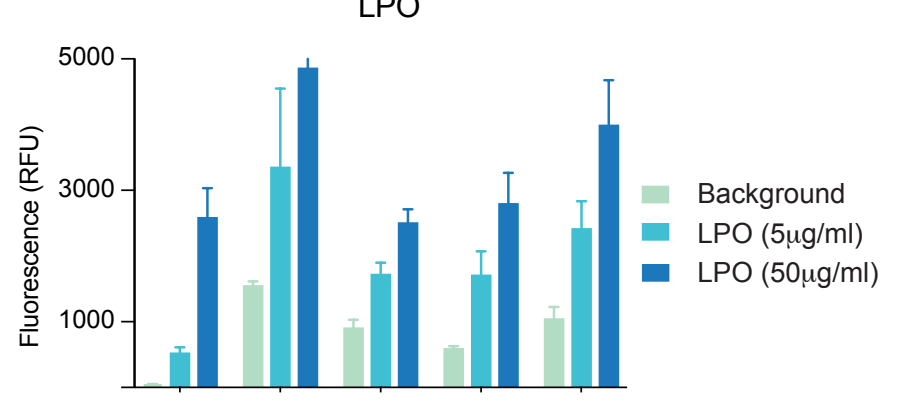




\section{Figure 5}

A

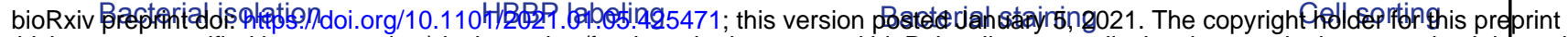
(which was not certified by peer review) is the author/funder, who has granted bioRxiv a license to display the preprint in perpetuity. It is made

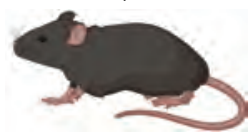

B

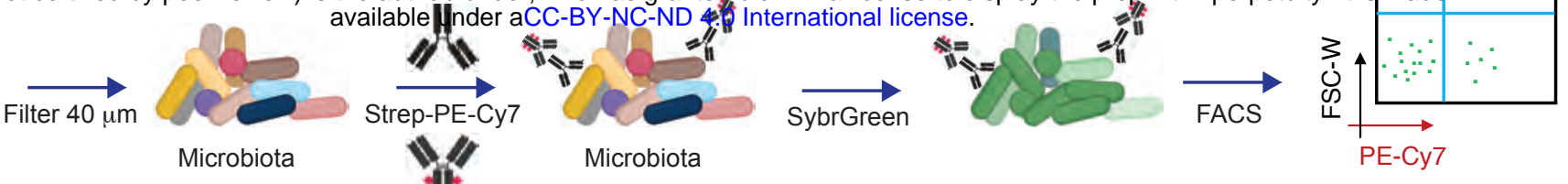

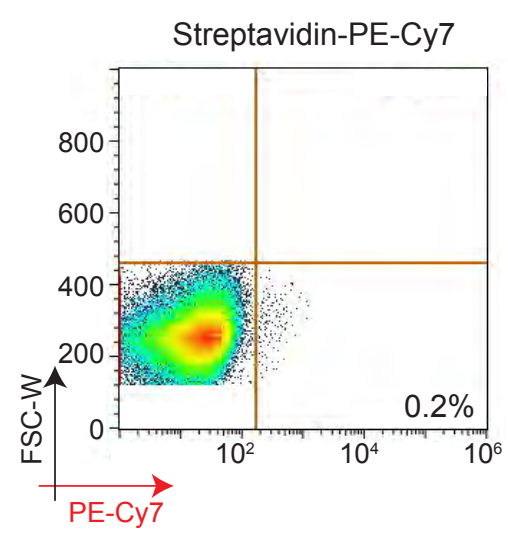

C

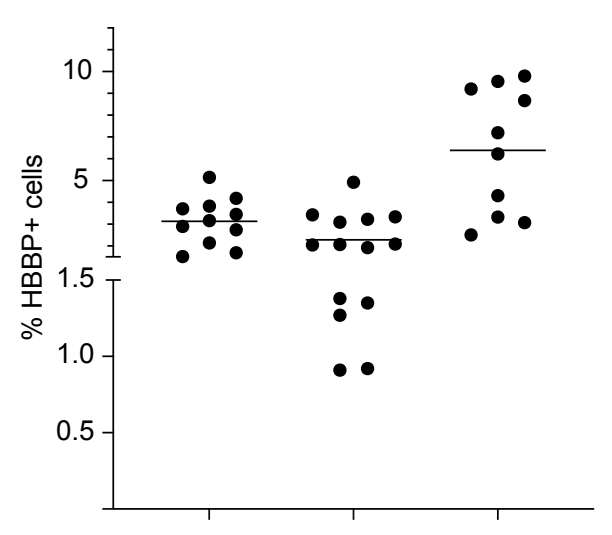
$\min \operatorname{exin} A^{1} \quad z A^{G} \quad$ LO
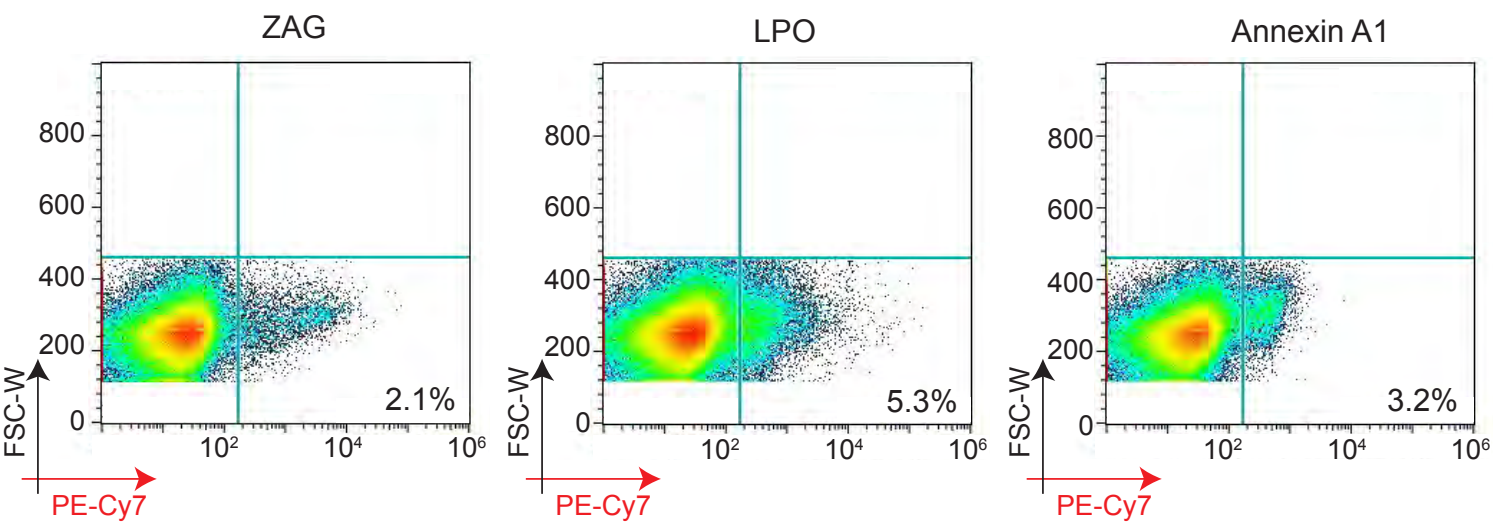

D

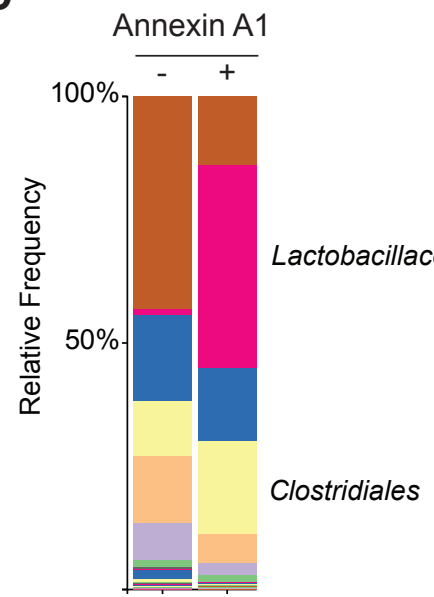

Clostridiaceae (family)

Lactobacillaceae (family) Lachnospiraceae (family)
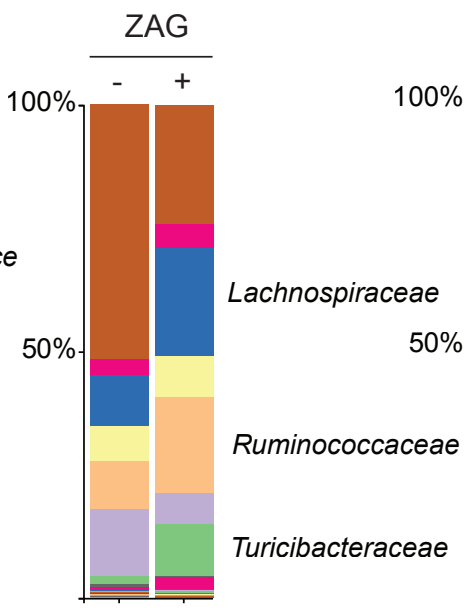

Clostridiales (order)

Ruminococcaceae (family) Muribaculaceae (family)
Erysipelotrichaceae

Turicibacteraceae

Coriobacteriaceae 


\section{Figure S1}

A bioRxiv preprint doi: https://doi.org/10.1101/2021.01.05B25471; this version posted January 5, 2021. The copyright holder for this preprint (which was not certified by peer review) is the author/funder, who has granted bioRxiv a license to display the preprint in perpetuity. It is made

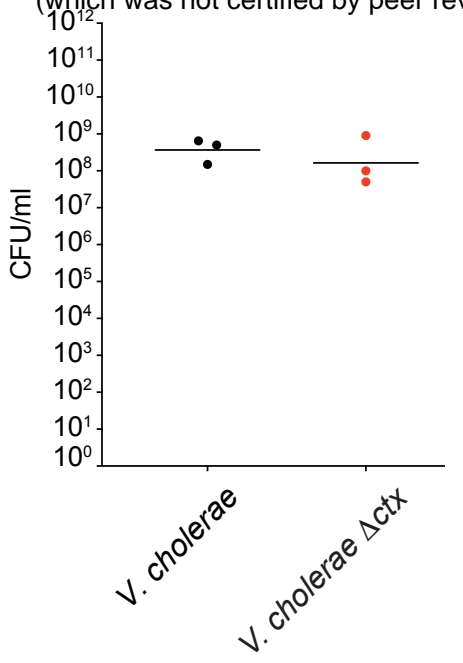
available under aCC-BSOPHC-ND 4.0 International license.

C

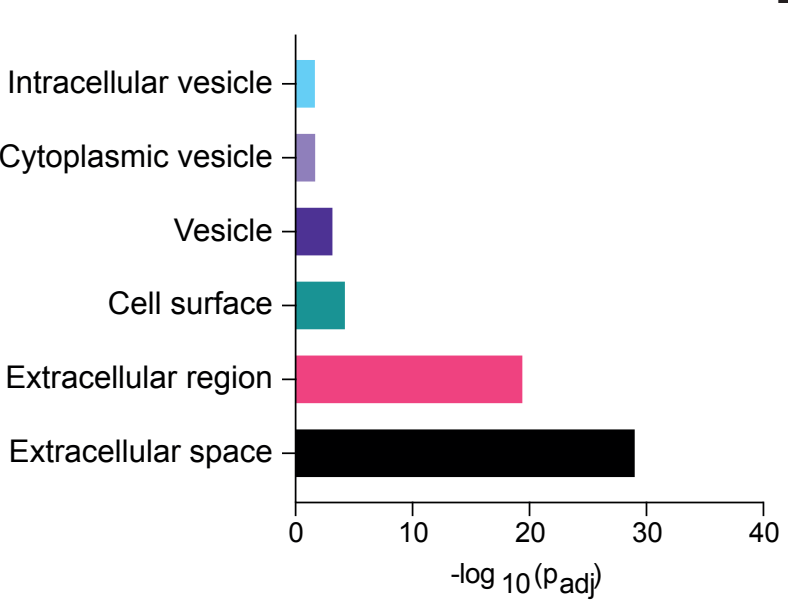

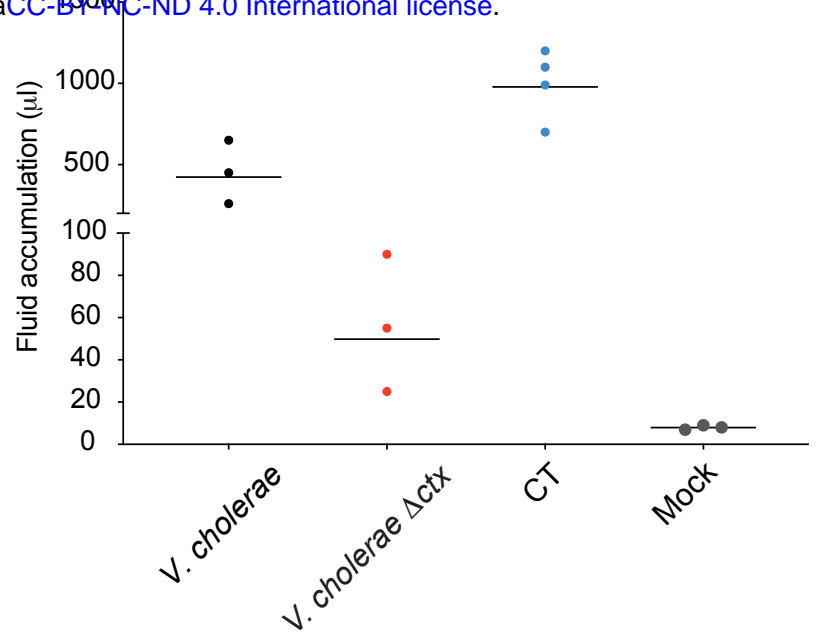

D

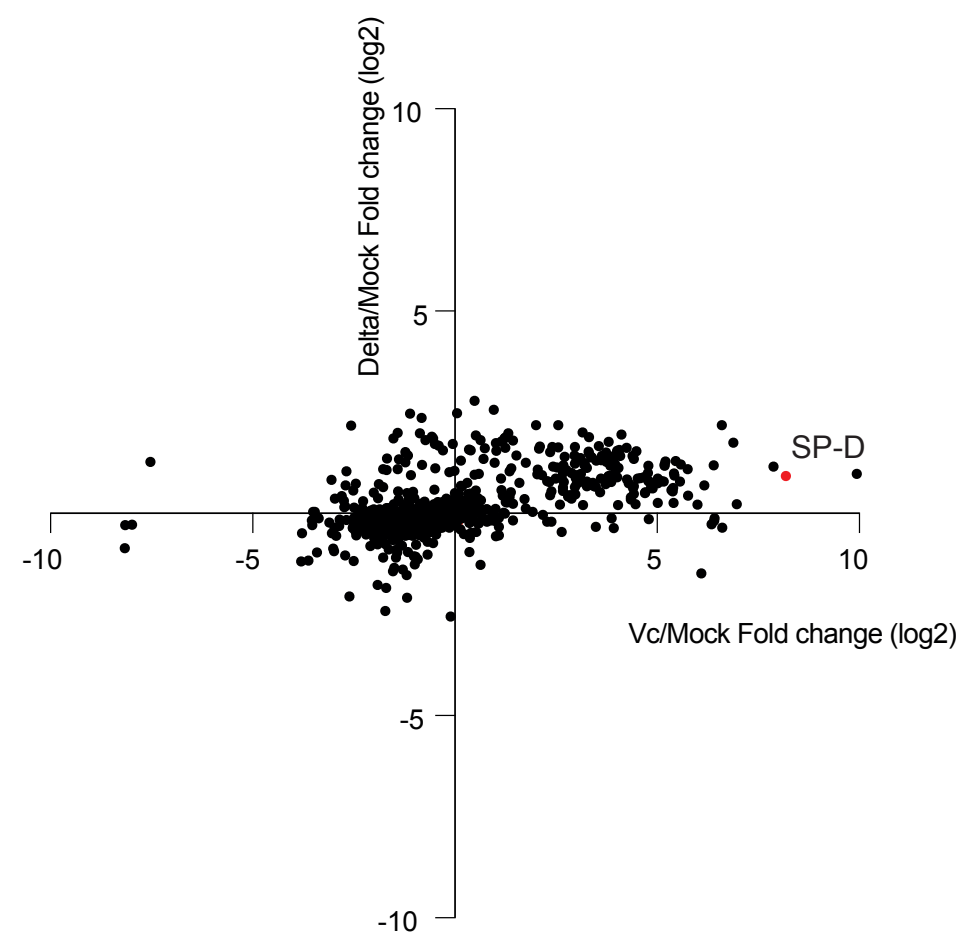


Figure S2

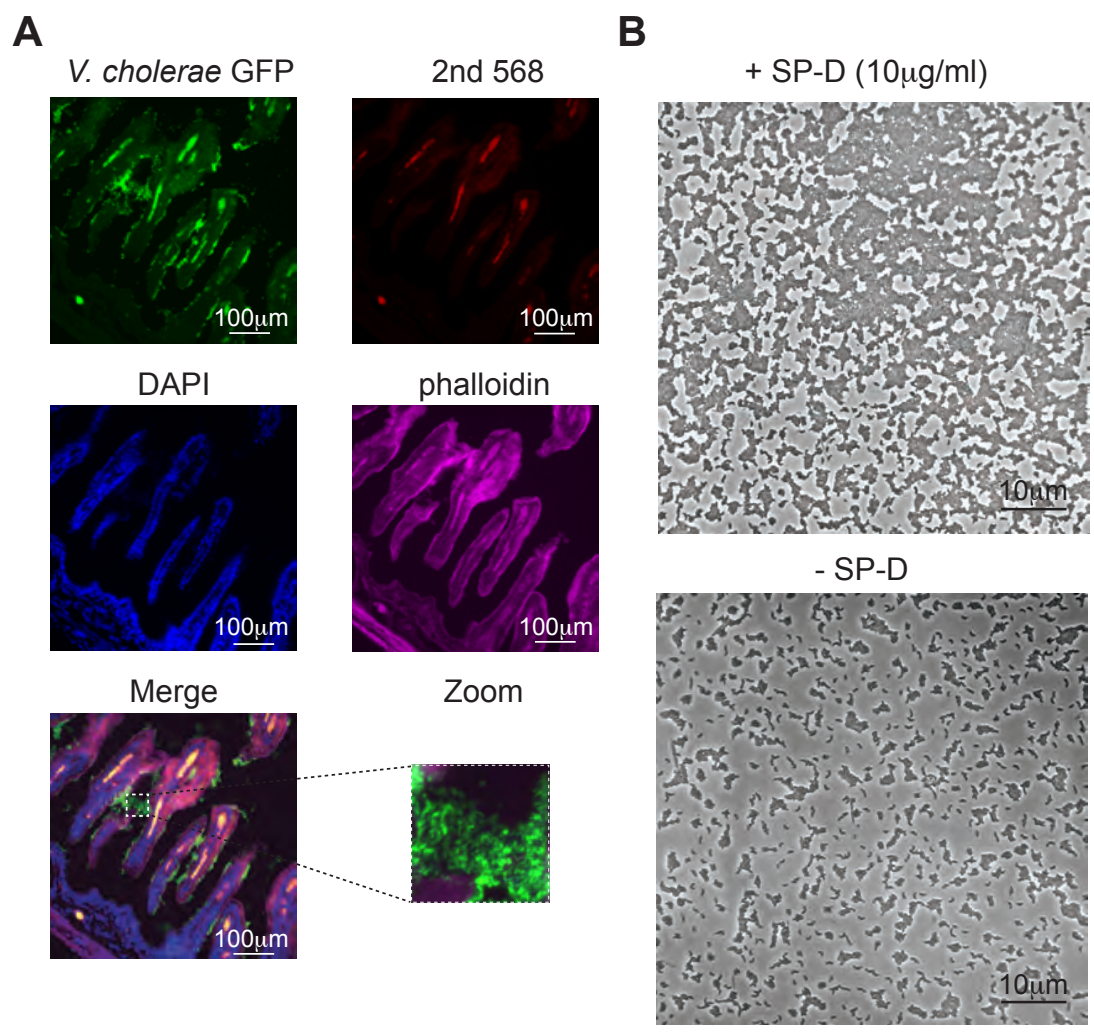




\section{Figure S3}

A bioRxiv preprint doi: htBs://doi.org/10.1101/2021.01.05.425471; this version posted January 5, 2021. The copyright holder for this preprint

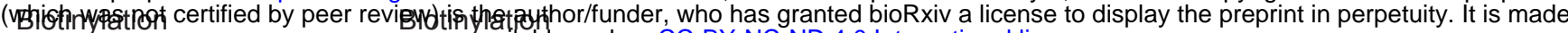

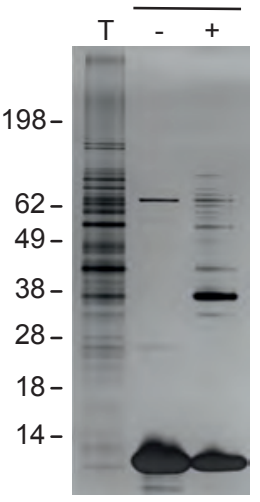
T - +

$198-$

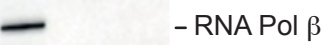

$62-$

49

$38-$

28 -

$18-$

14

C Biotinylation $T+\quad$

$198-$

62 -

49 -

$38-$

28 -

18 -

14 -
D

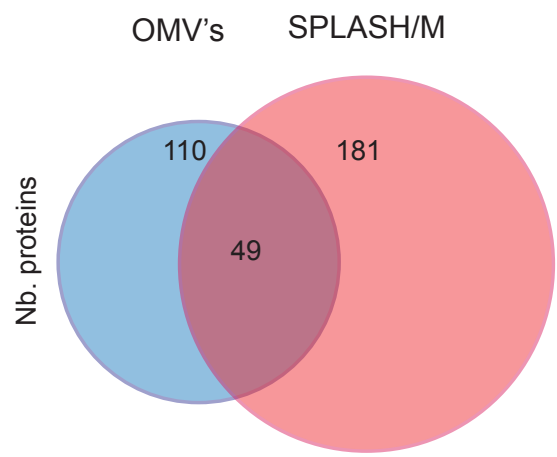




\section{Figure S4}

bioRxiv preprint doi: https://doi.org/10.1101/2021.01.05.425471; this version posted January 5, 2021. The copyright holder for this preprint A (which was not certified by peer review) is the author/funder, who has granted bioRxiv a license to display the preprint in perpetuity. It is made
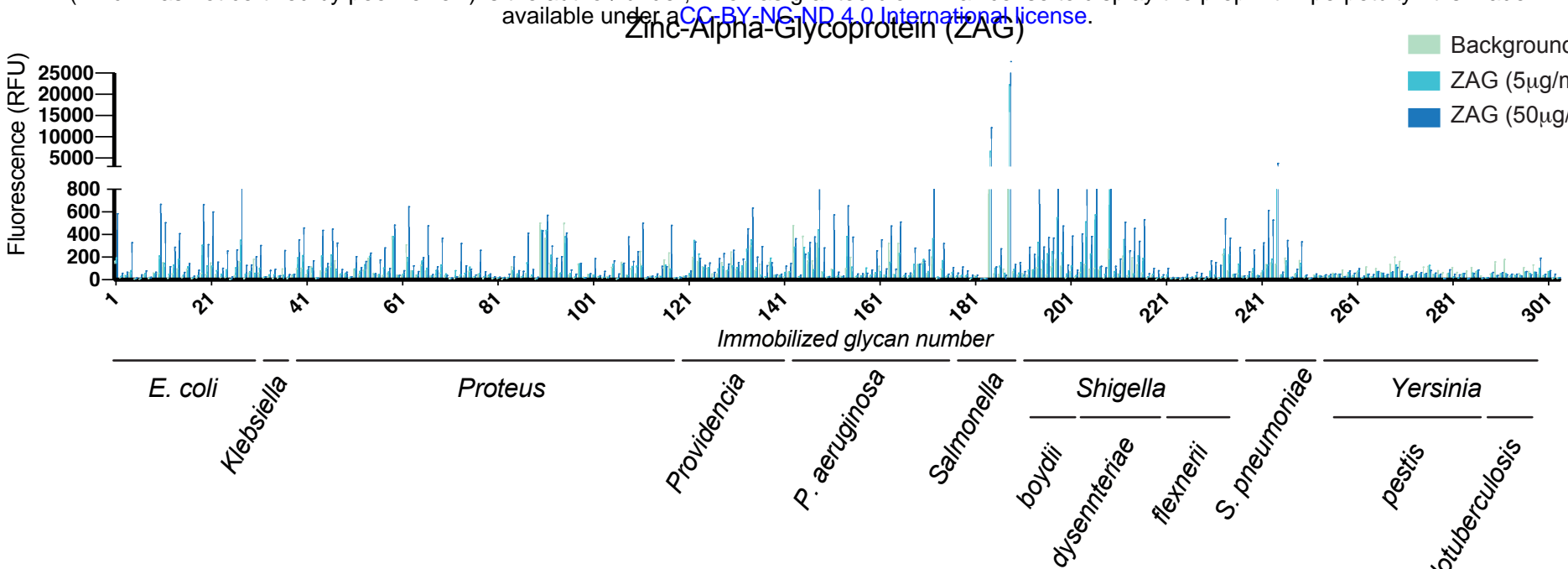

B

\section{Lactoperoxidase (LPO)}

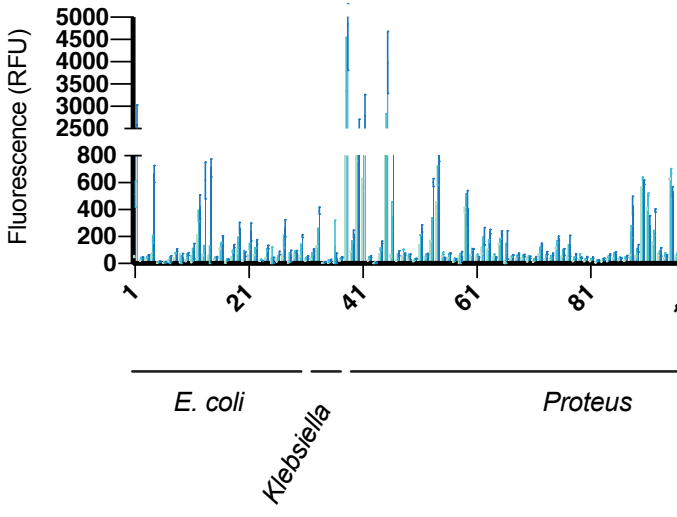

C

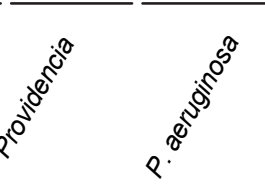

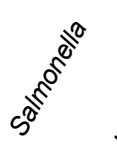

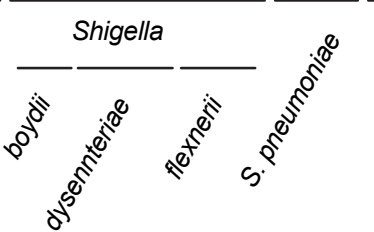

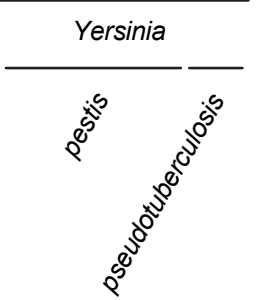

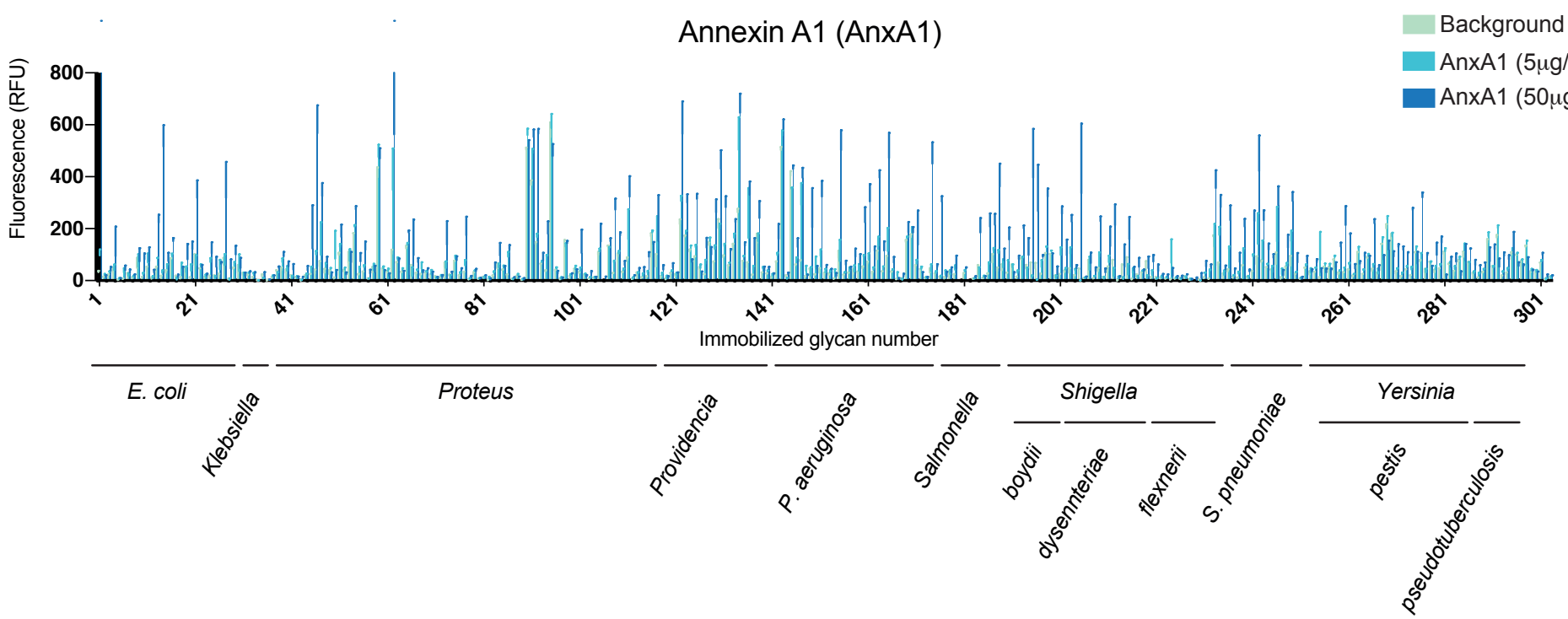


Figure S5

A

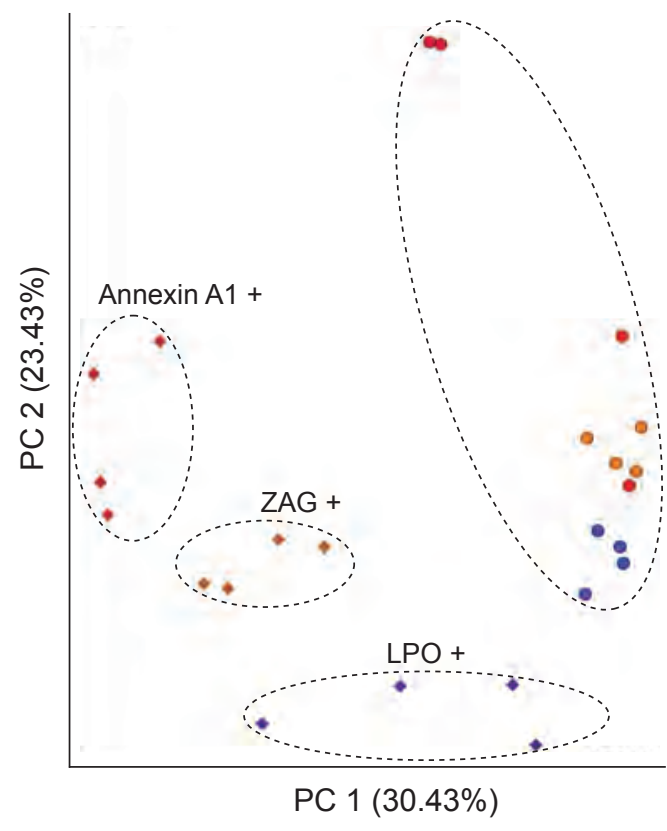

B

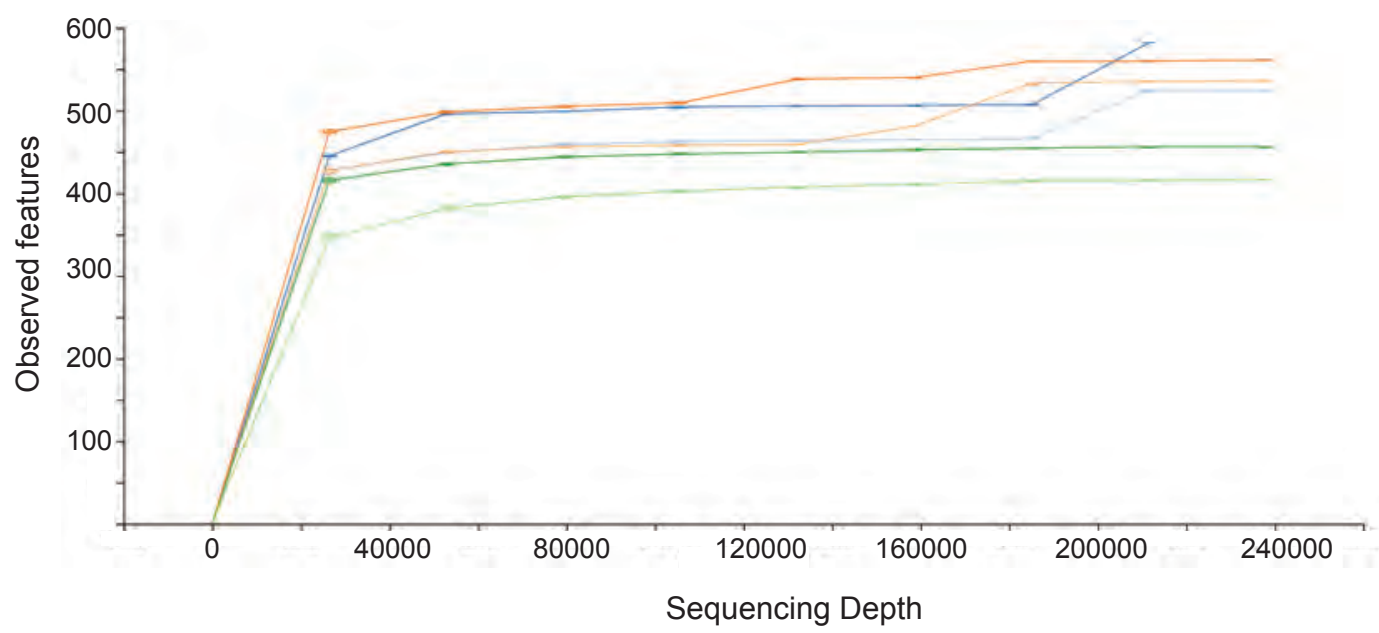

Annexin A1 -

- Annexin A1 +

- LPO -

- $\mathrm{LPO}+$

- ZAG -

- ZAG + 